Article

\title{
Incorporation of Geometallurgical Attributes and Geological Uncertainty into Long-Term Open-Pit Mine Planning
}

\author{
Nelson Morales ${ }^{1,2}$, Sebastián Seguel ${ }^{3}$, Alejandro Cáceres ${ }^{3}$, Enrique Jélvez ${ }^{1,2, *}$ \\ and Maximiliano Alarcón 1,2 \\ 1 Advanced Mining Technology Center, Universidad de Chile, Santiago 8370451, Chile; \\ nelson.morales@amtc.cl (N.M.); malarcon@delphoslab.cl (M.A.) \\ 2 Delphos Mine Planning Laboratory \& Department of Mining Engineering, Universidad de Chile, \\ Santiago 8370448, Chile \\ 3 GeoInnova, Santiago 7500032, Chile; sseguel@geoinnova.cl (S.S.); alejandro@geoinnova.cl (A.C.) \\ * Correspondence: enrique.jelvez@amtc.cl
}

Received: 10 December 2018; Accepted: 6 February 2019; Published: 13 February 2019

check for updates

\begin{abstract}
Long-term open-pit mine planning is a critical stage of a mining project that seeks to establish the best strategy for extracting mineral resources, based on the assumption of several economic, geological and operational parameters. Conventionally, during this process it is common to use deterministic resource models to estimate in situ ore grades and to assume average values for geometallurgical variables. These assumptions cause risks that may negatively impact on the planned production and finally on the project value. This paper addresses the long-term planning of an open-pit mine considering (i) the incorporation of geometallurgical models given by equiprobable scenarios that allow for the assessing of the spatial variability and the uncertainty of the mineral deposit, and (ii) the use of stochastic integer programming model for risk analysis in direct block scheduling, considering the scenarios simultaneously. The methodology comprises two stages: pit optimization to generate initial ultimate pit limit per scenario and then to define a single ultimate pit based on reliability, and stochastic life-of-mine production scheduling to define block extraction sequences within the reliability ultimate pit to maximize the expected discounted value and minimize the total cost of production objective deviations. To evaluate the effect of the geometallurgical information, both stages consider different optimization strategies that depend on the economic model to be used and the type of processing constraints established in the scheduling. The results show that geometallurgical data with their associated uncertainties can change the decisions regarding pit limits and production schedule and, consequently, to impact the financial outcomes.
\end{abstract}

Keywords: geometallurgy; geological uncertainty; mine planning; risk management

\section{Introduction}

\subsection{Mine Planning}

Strategic mine planning is a critical stage of a mining project that aims to capture the maximum economic potential of mineral resources. The decisions taken at this stage largely determine the expected cash flows of the project. For an open-pit mine, there are two important problems that strategic planning process must be addressed: the ultimate pit limit problem (it defines the mineable reserves) and the life-of-mine (LOM) production scheduling problem (it defines when the reserves should be extracted in order to maximize the net present value, or NPV). These problems depend considerably on the spatial variability of the deposit. The main input required for the mine planning 
process is the block model, which is a representation of the reservoir by means of generally regular block volumes. Each block of this model is assigned attributes of the deposit, such as its grade, density, rock type, geometallurgical variables, among others. These attributes are conventionally estimated using geostatistical estimation techniques from available drill-hole data and sampling [1].

In addition to the block model, the planning process requires other inputs, including estimates for long-term prices of commodities, mining and processing costs, and a number of technical parameters related to mine design.

One of the main results of the planning process is the production schedule, which indicates how and when the ore reserves will be extracted in order to maximize the total discounted value of the project and generating a financial forecast that commits the mine production over time. Then, the blocks must be scheduled for extraction over a set of years and a destination must be assigned to each one of them, while satisfying several constraints such as the slope in pit walls to ensure stability, limited availability of operational resources (transporting and processing), and maximum and/or minimum allowable concentrations of ore-grade or pollutants, also known as blending.

Figure 1 shows the main stages of traditional long-term mine planning process: for each individual block of the block model a value that represents its economic benefit is assigned, which depends on the recoverable metal content, commodity price and several operating costs, thus the final value of a block depends on whether it will be treated as ore or waste. Then nested pits are obtained using the methodology proposed by [2]. From the total number of generated nested pits, a selected number is used to define the phase sequence, based upon selected criterion (or criteria), for instance, minimum operational width that must be maintained to ensure an operative design or avoiding the gap problem [3,4]. Finally, a temporary production scheduling defines in every pushback when the different zones will be extracted and which of them will be processed, maximizing NPV of the operation and subject to a number of constraints such as slope, operational resources and/or blending. An iterative approach from phase sequence to production scheduling is usually performed because different combinations of phase sequences are evaluated and cut-off grades are optimized.

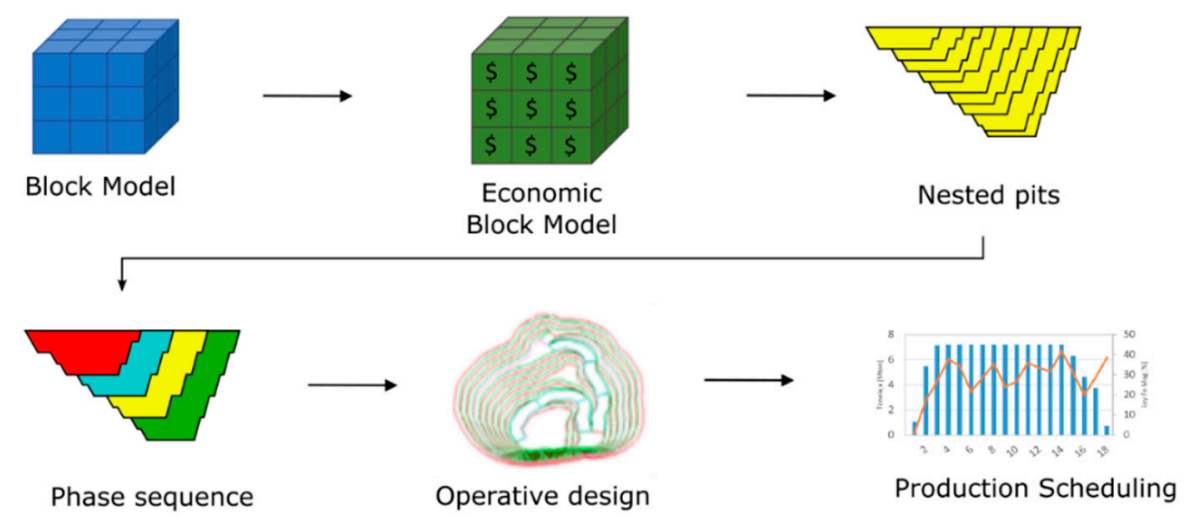

Figure 1. Traditional methodology for long-term open-pit mine planning (adapted with permission from [5]).

However, two main drawbacks of this methodology are: (i) the use of a single resource block model that is limited to in situ tons and grades, while metallurgical parameters are estimated without considering the spatial variability of these attributes, being often considered fixed values, and (ii) the time is not take into account as a key variable into nested pits definition, therefore net present value is only considered after phase sequence is computed. This is a critical issue for mine planning because the inability to quantify the impact of uncertainty on the performance of the downstream processing operations is a key reason why mining companies are often unable to meet production targets and financial forecasts. 


\subsection{Geometallurgy}

Many definitions of geometallurgy can be found in the literature (see [6-9] and references therein). In the context of this work, geometallurgy seeks to characterize and model the spatial variability of the deposit's attributes related to metallurgical performance. The result is a spatial model of the variables providing a useful basis for supporting mine planning, design and optimization of metallurgical processes, allowing a better understanding of mineral resources and a more realistic assessment of the project value during the planning stage. For example, the production scheduling stage can be improved by knowing the geometallurgical information, with their spatial distributions, enabling a better selection of the ore and the development of appropriate processing strategies based on this information. On the other hand, by considering the geometallurgical information also minimize the risk in a mining project, through an operational design that responds to potential events, such as the presence of contaminants in the ore. Therefore, a geometallurgical approach to mine planning is based on identifying these critical attributes and integrating them into block model in order to ensure that their variabilities are fully taken into account. Many studies [6,10-15] have shown that incorporating geometallurgical data can improve mine planning optimization process. A summary of the challenges and strategies for addressing mine planning and design is found in [16].

\subsubsection{Geometallurgical Variables}

Geometallurgical variables correspond to any type of rock attribute that has a positive or negative impact on the resources value. In general, non-linear behavior in metallurgical variables is expected and can be classified into two types [12]: primary and response.

Primary variables correspond to intrinsic rock properties. These variables can be measured directly and are generally used to predict metallurgical responses. As examples of this type of variables are: hardness, in-situ density, texture, alteration, ore grades and pollutant grades.

On the other hand, response variables are attributes of the rock that describe the responses to metallurgical processes, such as comminution and flotation. Among the most relevant metallurgical responses, the following variables are considered: metallurgical recovery, throughput rate (in tons per hour, or TPH), concentrate grade, grindability and liberation.

Metallurgical recovery and comminution performance are key parameters that directly affect planned production and hence the timing of cash flows and their prediction in the early stages of a mining operation (see [17] (chapter 3) and [18]). A brief description of the metallurgical recovery and comminution performance (as throughput rate) are presented as two geometallurgical variables that will be considered in this work. Indeed, they are identified as key sources of uncertainty that affect the mine planning process [19].

\subsubsection{Metallurgical Recovery}

Metallurgical recovery is one of the most relevant response variables of the processing plant. This parameter measures the fraction of metal that is recovered with respect to the amount of metal in the plant feed. Its spatial characterization is of great importance for mine planning due to the influence on the economic valuation of a deposit. The most common processing recovery tests are based either on leaching or flotation, for example, the recovery of sulfide ore is obtained experimentally in small-scale laboratory test [20].

\subsubsection{Comminution Performance}

The comminution performance expressed through a throughput rate model indicates the tons per hour (TPH) that can be processed in a comminution circuit. It mainly depends on the hardness of the ore, the size distribution (in feed and product) and the comminution equipment characteristics (nominal power, availability, etc.). Comminution performance is determined using ore crushing and grinding indices that are determined from specific laboratory tests. The most widely-used tests are [18]: 
Bond Ball Mill Work index (BWi), Bond Rod Mill Work index (RWi), Drop Weight index (DWi) and Resistance to Abrasion and Breakage index $\left(A^{*} b\right)$. A complete review of ore comminution performance tests can be found in [21].

The information obtained from the throughput rate models can be useful for the planning process, in particular, to improve destination allocation and the production scheduling. Minerals with lower TPH have longer times and could, therefore, potentially generate a bottleneck in the processing chain. Therefore, the decision to process this type of mineral should consider an associated opportunity cost, since minerals with higher TPH and at a higher rate, while minerals that have shorter processing times should be preferable for planning purposes.

As a final comment, the concept of varying plant throughput rate over the life of an operation and striking the correct balance between throughput and recovery in order to maximize NPV of a resource production plan is one that has received little attention in the literature thus far. Some works as presented by [22] show the metallurgical throughput-recovery relationship is an important factor in planning the extraction of the resource to feed a given process plant of fixed size since this impacts heavily upon the production schedule and therefore the total discounted value of the project. In this work these variables are conditionally co-simulated, using geostatistical techniques.

\subsection{Modeling the Uncertainty}

The uncertainties associated with grades and geometallurgical variables are another important aspect that must consider the mine planning process. Geological uncertainty arises from a limited knowledge of the deposit because of finite sampling (restricted by exploration costs). This means that the deposit can only be estimated with a certain precision, which will depend mainly on three aspects [23]: (i) the number, location and quality of the samples taken, (ii) the type of deposit, and (iii) the method used to generate the estimates.

Traditional resource estimation techniques like kriging [1] are conventionally accepted for the estimation of ore reserves. However, these techniques generate a smoothed representation of the deposit which raises problems with its use [24]: the effect of in situ variability and uncertainty of the deposit in the optimization process (ultimate pit limit and LOM production scheduling), using models with expected values for a non-linear process, causing deficiencies in production schedules and generating potential discrepancies between planned and actual production.

Conditional simulation has become a well-recognized geostatistical method for quantifying geological uncertainty and assessing risk in mine planning: it refers to a simulation that honors the available data from drill holes and may be used to generate equally probable representations of in situ orebody variability [25]. Applying a simulation approach that places no requirement on variable linearity is the best approach for metallurgical properties [26]. There are different approaches to apply the simulated representations to mine planning, for example [27] (and references therein), where all of them show that geological uncertainty have important effects on ultimate pits and production schedules. Figure 2 shows both traditional and uncertainty-based approaches. In the first case a single, smoothed estimated block model is used as main input to mine planning. In the second case, a set of equiprobable conditional simulated block models is used to generate a production schedule. The project indicators in the second case are presented as probability distributions. There exist several forms to use the information from simulations: quantifying risk on the set of production schedules obtained (one for each simulation), and from them, making a decision of a single schedule (or ultimate pit) by using some criterion, for instance, based on reliability. Other approaches are based on simulated annealing [28-30], risk control by using chance-constrained programming model [31] and stochastic integer programming [32] (see Section 1.4). 


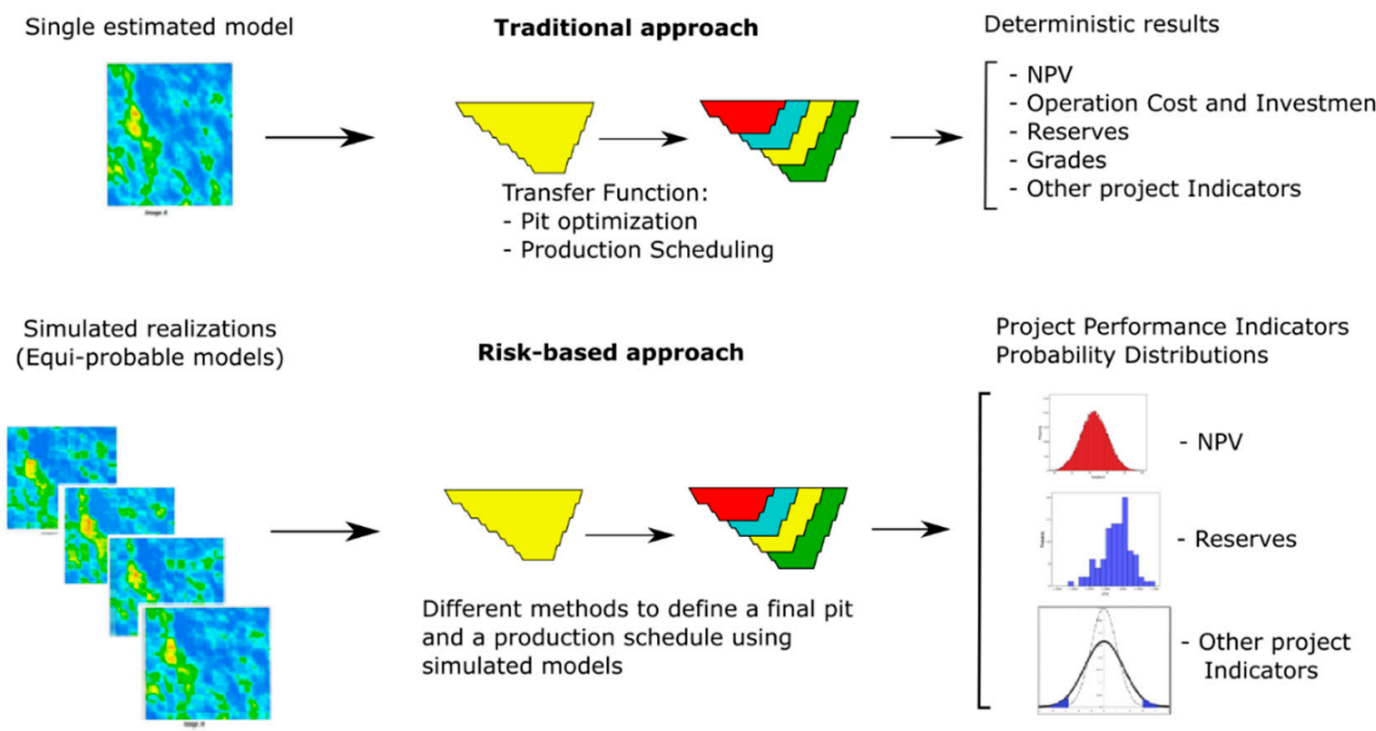

Figure 2. Traditional and risk-based approaches applied in mine planning (adapted with permission from [5]).

\subsection{Background on Direct Block Scheduling}

Currently, the optimal pit limits and LOM production scheduling process are carried out using the nested pit methodology, the foundations of which date back to 1965 [2]. An alternative approach that aims to integrate all the steps presented in Figure 1 is based on mathematical programming and known as Direct Block Scheduling (DBS). This approach aims to generate optimal pit limits and production schedules, where a single optimization process determines the best block-support extraction period, so the scheduled volumes of mineral already comply with some constraints, such as mining or plant capacities [33]. While this approach is theoretically better, it has the issue of the computational complexity of solving the mathematical problem, which can be very large [34]. For this reason, many authors have worked on developing schemas to approach variations of this problem (see [35-37] and references therein).

Figure 3 briefly depicts the deterministic DBS methodology for mine production scheduling. From the left, the block model and all parameters and constraints are fed into an optimization model that, when solved, produces a production schedule. Note that DBS approach cannot produce solutions that violate a constraint, in contrast with traditional methodology, where compliance with the constraints must be ensure for the mine planner.

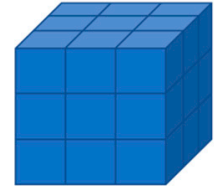

$$
\begin{array}{ll}
* \text { Time periods } \\
+\quad & * \text { Parameters } \\
& * \text { Constraints }
\end{array}
$$

\section{Block Model}

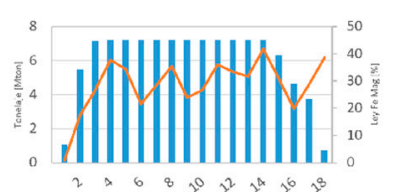

Production Scheduling

Figure 3. Deterministic Direct Block Scheduling approach, where production scheduling comes out right from solving an optimization model.

It is worth noting that the optimizer might be able to further increase dollar value (USD) if it is able to make cut-off grade (or USD/mill/hour) optimization while it optimizes the production schedule.

Finally, it should be pointed out that the generality in the modeling provided by mathematical programming allows the simultaneous inclusion of a large number of representations of the block model (conditional simulations), for example, to increase the expected value of the mining project, and/or to reduce the risk of failure to meet production goals, allowing to generate more robust 
schedules, as shown in [27,38-40]. In this case, the direct block scheduling is addressed under a stochastic optimization approach. The main advantage of consider the all information given by conditional simulations allows for the integration of in situ deposit variability and uncertainty directly into the optimization process, producing a single optimal schedule across all simulations.

\subsection{Contribution of the Research}

This paper addresses the long-term planning of an open-pit mine incorporating simulated geometallurgical models that allow to consider the spatial variability and the uncertainty of the mineral deposit, quantifying the risk and assessing the impact on mine planning decisions such as ultimate pit limit and life-of-mine production scheduling along a number of simulated scenarios by means of a stochastic Direct Block Scheduling approach, where the entire set of realizations are simultaneously used into a stochastic model to maximize the expected discounted value of the project, and simultaneously, to minimize the discounted total cost associated to deviation of the production objectives.

A real copper-molybdenum deposit is used as case study, for which four variables were simulated: copper and molybdenum grades, copper recovery and comminution performance (mill throughput as tonnes per hour), then the optimization of the planning process not only takes into account the ore grades but it also considers the effect of the recoverable copper metal together with the amount of ore mineral that can effectively be processed by the grinding circuit given its hardness. The results show that the proposed methodology can improve the expected value of the project and to control the risk of losses caused by deviation of production objectives, changing the decisions about pit limits and production schedules and, consequently, impact the financial outcomes. This work follows the line of other contributions that have incorporated the geological uncertainty into open-pit design and planning, such as [41,42], but, unlike these papers, this work additionally incorporates simulations on geometallurgical attributes (not only grades, but also recovery and mill throughput), and it makes use of non-traditional approach based on stochastic direct block scheduling algorithms. Therefore, this work provides mine planning and design engineers a step-by-step procedure to assess the impact of geometallurgical variability on mine planning studies through modern DBS techniques, contrary to traditional approach based on nested pits.

\section{Materials and Methods}

\subsection{Notation}

Consider the following notation: Let $B$ be the block model and blocks in $B$ will be denoted by $b$ and $b^{\prime} . \operatorname{PREC}(b)$ represents the subset of blocks with a precedence arc from block $b$ (see Figure 4 ). The set of precedence arcs is determined by a slope angle and height (cone of precedence). The block model has $|R|$ realizations of four simulated variables: copper $(\mathrm{Cu})$ and molybdenum (Mo) grades, copper recovery and comminution performance (mill throughput as tonnes per hour). Additionally, an estimated block model per simulated variable E-Type (which consider the average of each variable along realizations) is considered for comparison (in this case, $r=$ etype).

For each block $b$ a number of attributes are given, such as: (i) rock tonnage $T_{O N}$ (in tonnes),

(ii) copper and molybdenum grades from realization $r\left(G_{b r}^{c u}\right.$ (in \%) and $G_{b r}^{m o}$ (in ppm), respectively),

(iii) copper metallurgical recovery $\boldsymbol{R}_{b r}^{c u}$ from realization $r$ (in \%), and (iv) comminution performance $\mathbf{T P H}_{b r}$ from realization $r$ (in tonnes/hour). The copper-molybdenum concentrate tonnage is denoted as $\mathbf{T O N}_{b}^{c c}$ (in tonnes). Also, a comminution performance of copper-molybdenum concentrate $\mathbf{T P} \boldsymbol{H}_{b}^{c c}$ (in tonnes/hour) is given.

The E-Type variables are: $\overline{G_{b}^{c u}}$ for $\mathrm{Cu}$ grade, $\overline{G_{b}^{m o}}$ for Mo grade and $\overline{R_{b}^{c u}}$ for Cu recovery. In the case of processing molybdenum, the recovery $\boldsymbol{R}^{m o}$ (in (\%)) is always assumed fixed and $\boldsymbol{H}$ is the average processing time (in hours). 
To generate an economic block model, commodity prices and several costs involved in the mining process are presented in Table 1 .

Given that the interest is to assess how different geometallurgical variables impact the mine planning decisions, four different schemes will be used to construct economic models. Table 2 summarizes the cases that are evaluated, indicating how an attribute is considered in the assessment. The following schemes will be considered: in Scheme 1 (base case) the uncertainty is not considered at all, i.e., all variables are considered deterministic (1). In Scheme 2, the realizations of $\mathrm{Cu}$ and Mo are considered, assuming $\mathrm{Cu}$ recovery given by E-Type model (2). In Scheme 3 the simulated variables $\mathrm{Cu}$ grade, Mo grade and Cu recovery are simultaneously considered (3). Finally, in Scheme 4 all simulated variables are considered and the profit obtained from a block will be weighted according to its throughput rate and recoverable metal content (4).

An economic block value $v_{b r s}$ is assigned to each block $b$ and realization $r$ according scheme $s$

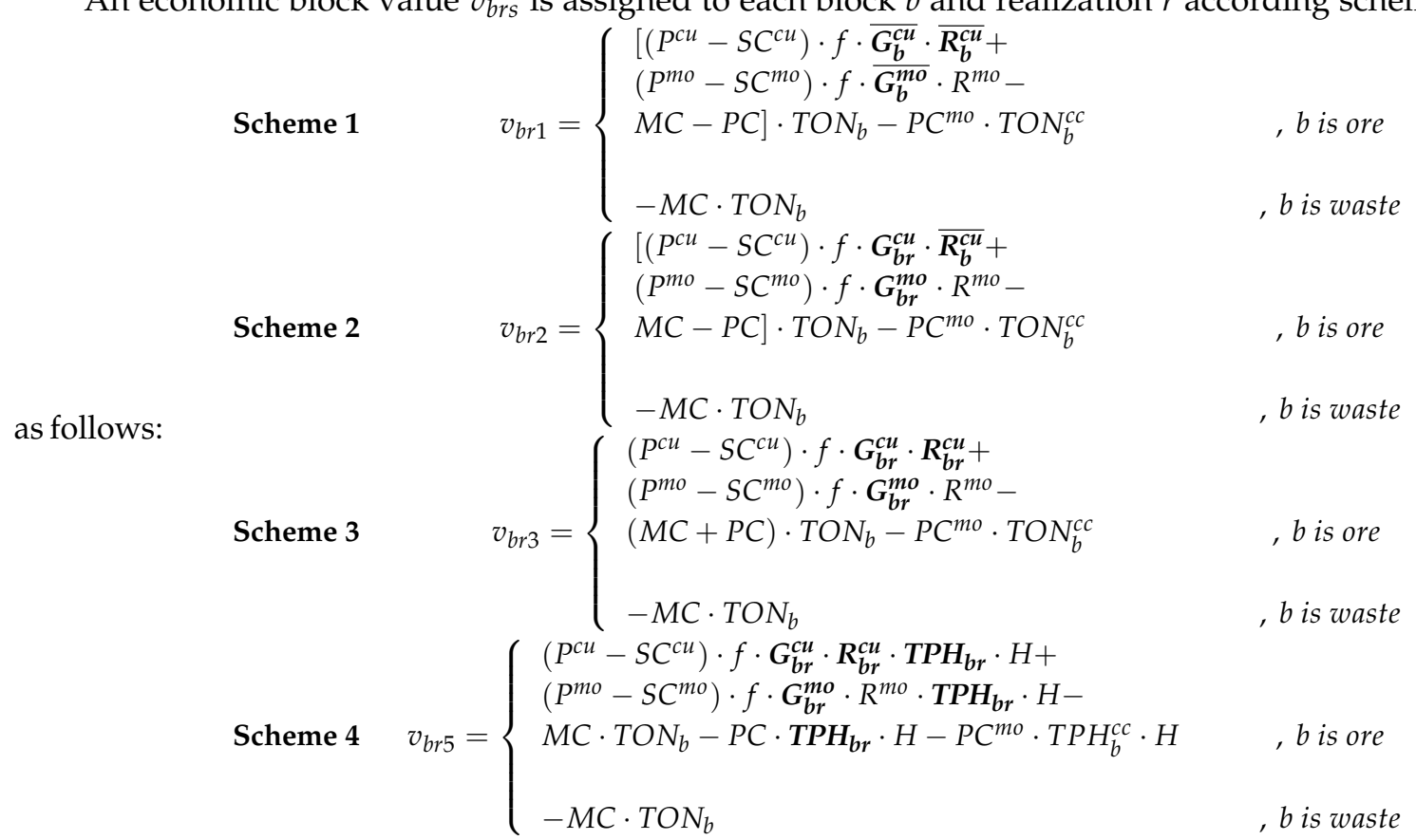

where $f=2204.62 \mathrm{lb} /$ ton. As can be seen, in each scheme the economic block value depends of the classification between ore and waste of each block: if a block $b$ is assigned as ore then its economic value is positive and given by the income obtained from the sale of the metal minus the processing costs to obtain it. Otherwise, the economic value is negative and corresponds to the cost of extracting it and sending it to the waste dump.

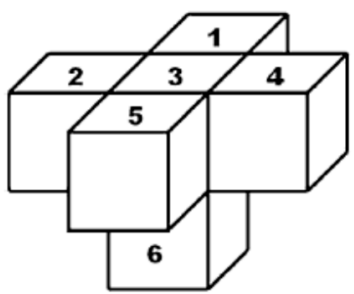

(a)

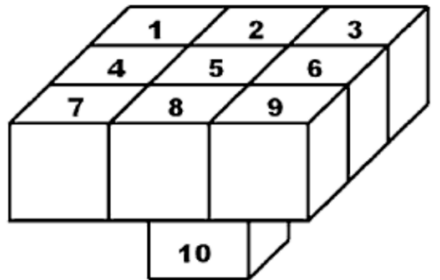

(b)

Figure 4. Two approximations of the extraction in an open-pit mine. (a) In order to extract block 6 first must be extracted blocks 1 to 5, therefore there are five precedence arcs from block 6. (b) In order to extract block 10 first must be extracted block 1 to 9: there are nine precedence arcs from block 10 [43]. 
Table 1. Summary of economic parameters for block valuation.

\begin{tabular}{ccc}
\hline Symbol & Unit & Parameter \\
\hline$P^{c u}$ & $\mathrm{USD} / \mathrm{lb}$ & Cu price \\
$P^{m o}$ & $\mathrm{USD} / \mathrm{lb}$ & Mo price \\
$S C^{c u}$ & $\mathrm{USD} / \mathrm{lb}$ & Cu selling cost \\
$S C^{m o}$ & $\mathrm{USD} / \mathrm{lb}$ & Mo selling cost \\
$M C$ & $\mathrm{USD} /$ ton & Mining cost \\
$P C$ & $\mathrm{USD} /$ ton & Processing cost (main) \\
$P C^{m o}$ & $\mathrm{USD} /$ ton & Mo processing cost \\
\hline
\end{tabular}

Table 2. Summary of schemes on simulated variables to be assessed on economic block values.

\begin{tabular}{ccccc}
\hline Scheme & Cu Grade & Mo Grade & Cu Recovery & TPH \\
\hline 1 & $x$ & $x$ & $x$ & $x$ \\
2 & $\checkmark$ & $\checkmark$ & $x$ & $x$ \\
3 & $\checkmark$ & $\checkmark$ & $\checkmark$ & $x$ \\
4 & $\checkmark$ & $\checkmark$ & $\checkmark$ & $\checkmark$ \\
\hline
\end{tabular}

\subsection{Ultimate Pit Limit}

The ultimate pit limit problem (UPIT) seeks to determine the subset of blocks of the deposit where the extraction will be carried out, maximizing the undiscounted economic profit and meeting the requirements of the maximum allowed slope angle to ensure the stability of the pit walls. This problem, therefore, does not take into account the time dimension nor operational resource capacities [44].

By using integer programming, the ultimate pit limit for a given realization $r$ and scheme $s$ can be found solving the following problem:

$$
\begin{array}{cr}
\quad(U P I T) & \max \sum_{b \in B} v_{b r s} \cdot x_{b} \\
x_{b} \leq x_{b^{\prime}} & \forall b \in B, b^{\prime} \in \operatorname{PREC}(b), \\
x_{b} \in\{0,1\} & \forall b \in B,
\end{array}
$$

where $x_{b}$ is a binary variable equal to 1 if block $b$ belongs to ultimate pit limit and 0 otherwise. Objective function (5) represents the undiscounted total profit of selected blocks. Constraints (6) ensure that, in order to extract a block, the set of precedence blocks must have been extracted before, and constraints (7) set the nature of variables. For this problem there exist fast algorithms to solve it [45-48]. Note that this model solves separately for each scenario an ultimate pit limit.

From the obtained results, an analysis based on simulations is equivalent to make mine planning under perfect information of the deposit, that is, for each realization the best ultimate pit will be found providing an estimate for the key indicators of the robust ultimate pit resulting when having perfect knowledge. Therefore, a risk analysis and a comparison between the results obtained from simulations and deterministic model, such as kriging or E-Type (see [1]) is possible. An option is to configure a probabilistic model that indicates the probability that each block has of belonging (or not) to the robust optimal pit limit for the real resources, based on simulated pit limits.

\subsection{LOM Production Scheduling}

The second stage consists of scheduling the final pits obtained above. Two approaches will be addressed: (i) solving the deterministic schedule by using E-Type models without uncertainty, and then making risk analysis along the simulated scenarios, or (ii) solving a stochastic direct block scheduling program, where the entire set of scenarios are simultaneously considered into a multi-objective optimization approach. 


\subsubsection{Deterministic Direct Block Scheduling}

According this approach, the schedule is obtained by solving the problem (SCHED) given by Equations (8)-(13) based on a direct block scheduling approach, therefore, nested pits are not used to guide the sequence. Note that (SCHED) supports one scenario at time, so the uncertainty is not considered in this model. In this case, the following scheduling scheme will be considered:

- Scheduling Scheme 1: the economic block model $v_{b r 1}$ is constructed according Equation (1), that is, just considering deterministic variables (E-Type models). The minimum and maximum processing capacities are assumed fixed.

By using a DBS approach, the LOM production schedule in a planning horizon $T=\{1,2, \ldots,|T|\}$ can be found solving the following problem:

$$
\begin{gathered}
(S C H E D) \quad \max \sum_{\substack{b \in B \\
t \in T}} \frac{1}{(1+d)^{t}} \cdot v_{b r 1} \cdot\left(x_{b t}-x_{b, t-1}\right) \\
x_{b t} \leq x_{b^{\prime} t} \quad \forall b \in B, b^{\prime} \in \operatorname{PREC}(b), t \in T \\
x_{b, t-1} \leq x_{b t} \quad \forall b \in B, b^{\prime} \in \operatorname{PREC}(b), t \in T \\
M_{t}^{-} \leq \sum_{b \in B} \operatorname{TON}_{b} \cdot\left(x_{b t}-x_{b, t-1}\right) \leq M_{t}^{+} \quad \forall t \in T \\
P_{t}^{-} \leq \sum_{b \in B} \text { attribute }_{b} \cdot\left(x_{b t}-x_{b, t-1}\right) \leq P_{t}^{+} \quad \forall t \in T \\
x_{b t} \in\{0,1\} \quad \forall b \in B, t \in T
\end{gathered}
$$

where $x_{b t}$ is a binary variable equal to 1 if block $b$ is extracted in periods $1, \ldots, t$ and 0 otherwise. Objective Function (8) represents the discounted total profit of scheduled blocks by using a discount rate $d$. Constraints (9) ensure that, in order to extract a block $b$, the set of precedence blocks PREC $(b)$ must have been extracted before. Constraints (10) ensure that each block can be extracted no more than once. Constraints (11) require that minimum $M_{t}^{-}$and maximum $M_{t}^{+}$extracted tonnages are satisfied each period $t$. Constraints (12) limit between $P_{t}^{-}$and $P_{t}^{+}$the processed material given by a general attribute according scheduling scheme per period $t$, for example, processing ore tonnages. Finally, Constraints (13) set the nature of variables. If all blocks inside ultimate pit must be extracted, then $x_{b|T|}=1 \forall b \in B$ is an additional set of constraints.

In the scheduling Scheme 1, the attribute bounded is determined as indicated in Equation (14) and represents the ore tonnage (OTON).

Scheduling Scheme $1 \quad$ attribute $_{\boldsymbol{b}}=\mathrm{OTON}_{b}=\left\{\begin{array}{c}T_{O N_{b},} \text {, if } b \text { is ore } \\ 0, \text { if } b \text { is waste }\end{array} \quad \forall b \in B\right.$

\subsubsection{Stochastic Direct Block Scheduling}

Contrary to the approach developed in Section 2.3.1, where a single schedule is obtained with E-Type scenarios, in this section a stochastic approach is formulated, with a model whose input is the entire set of scenarios in one-run to compute a single robust schedule, maximizing the discounted expected value and simultaneously minimizing the uncertainty total cost associated with the deviations of the production objectives. In this case, the following scheduling schemes will be considered:

- Scheduling Scheme 2: the economic block model $v_{b r 2}$ is constructed according (2), therefore two simulated variables ( $\mathrm{Cu}$ grade and Mo grade) are considered. Minimum/maximum processing capacities are fixed. 
- Scheduling Scheme 3: the economic block model $v_{b r 3}$ is constructed according (3), therefore three simulated variables ( $\mathrm{Cu}$ grade, Mo grade and $\mathrm{Cu}$ recovery) are considered. As before, minimum/maximum processing capacities are fixed.

- Scheduling Scheme 4: the economic block model $v_{b r 4}$ is constructed according (4), but processing capacity constraint per period changes. While in the previous cases the maximum processing capacities per period are considered in terms of tonnages, in this case the total available times at the milling plant is considered at a given period as constraint. For this purpose, the milling hours for each block are calculated based on TPH model. Therefore, in this case, the four simulated variables are considered ( $\mathrm{Cu}$ grade, Mo grade, $\mathrm{Cu}$ recovery and TPH).

By using the stochastic DBS approach, the LOM production schedule for a given scheduling scheme $s$ in a planning horizon $T=\{1,2, \ldots,|T|\}$ can be found solving the following problem:

$$
\begin{aligned}
& \left(S T O_{s}\right) \quad \max \frac{1}{R}\left(\sum_{\substack{b \in B \\
t \in T \\
r \in R}} \frac{1}{(1+d)^{t}} \cdot v_{b r s} \cdot\left(x_{b t}-x_{b, t-1}\right)-\sum_{\substack{t \in T \\
r \in R}} c p_{r t}^{+} \cdot u_{r t}^{+}+c p_{r t}^{-} \cdot u_{r t}^{-}\right) \\
& x_{b t} \leq x_{b^{\prime} t} \quad \forall b \in B, b^{\prime} \in \operatorname{PREC}(b), t \in T \\
& x_{b, t-1} \leq x_{b t} \quad \forall b \in B, b^{\prime} \in \operatorname{PREC}(b), t \in T \\
& M_{t}^{-} \leq \sum_{b \in B} \operatorname{TON}_{b} \cdot\left(x_{b t}-x_{b, t-1}\right) \leq M_{t}^{+} \quad \forall t \in T \\
& \sum_{b \in B} \text { attribute }_{b r} \cdot\left(x_{b t}-x_{b, t-1}\right)-u_{r t}^{+} \geq P_{t}^{-} \quad \forall r \in R, t \in T \\
& \sum_{b \in B} \text { attribute }_{b r} \cdot\left(x_{b t}-x_{b, t-1}\right)+u_{r t}^{-} \leq P_{t}^{+} \quad \forall r \in R, t \in T \\
& x_{b t} \in\{0,1\} \quad \forall b \in B, t \in T \\
& u_{r t}^{+}, u_{r t}^{-} \geq 0 \quad \forall r \in R, t \in T
\end{aligned}
$$

where $x_{b t}$ is as defined in (SCHED), $u_{r t}^{+}, u_{r t}^{-}$are continuous variables representing the deviations in tonnes (surplus and shortage, respectively) of production objectives and $c p_{r t}^{+}, c p_{r t}^{-}$represent the unitary costs (surplus and shortage, respectively), for each scenario and time period. Objective Function (15) includes two parts: to maximize the expected discounted total profit of scheduled blocks along horizon $T$, and to minimize the expected discounted cost associated to deviation of production objectives, by using a discount rate $d$. Constraints (16) ensure that, in order to extract a block $b$, the set of precedence blocks PREC $(b)$. must have been extracted before. Constraints (17) ensure that each block can be extracted no more than once. Constraints (18) require that minimum $M_{t}^{-}$and maximum $M_{t}^{+}$extracted tonnages are satisfied each period $t$. Constraints (19) and (20) limit the minimum $P_{t}^{-}$and maximum $P_{t}^{+}$processing resource consumption given by a general attribute according scheduling scheme per period and scenario, for example, processing ore tonnages or processing tonnages per hour by using the TPH variable. Finally, Constraints (21) and (22) set the nature of variables.

In the scheduling Schemes 2 and 3, the attribute bounded is determined as indicated in Equation (23) and represents the ore tonnage.

Scheduling Scheme 2,3 attribute $_{b r}=$ OTON $_{b r}=\left\{\begin{array}{c}T_{O N_{b}, \text { if } b \text { is ore in scenario } r} \quad \forall b \in B, \\ 0, \text { if } b \text { is waste in scenario } r \quad r \in R\end{array}\right.$

In the scheduling Scheme 4, the attribute is given by Equation (24). In this case the throughput rate is limited by the available processing hours per year. It is also assumed that the processing plant 
is the bottleneck of the operation, therefore, the estimated grinding hours of each block given by the geometallurgical model (TPH) will be used to saturate the capacities. Note that in this case the processed ore tonnages at each period will be determined after the production schedule be obtained.

Scheduling Scheme 4

attribute $_{b r}=\frac{O T O N_{b r}}{T P H_{b r}}$

$\forall b \in B, r \in R$

Since the problems (SCHED) and (STO) have a large size (usually millions of blocks and tens of periods involved), a heuristic algorithm is necessary to find a good feasible solution of the problem. The proposed heuristic algorithm consists of a combination between an incremental greedy approach and a block preselection based on expected extraction times, which is known as ETInc and described in [49]. The results obtained may be useful to make risk analysis to key indicators such as ore tonnages and discounted total value.

The steps of the methodology for obtaining ultimate pit limit and LOM production schedule from simulated and E-Type block models can be summarized through the diagram in the Figure 5: A number of simulated (Cu-Mo grades, $\mathrm{Cu}$ recovery, TPH) and deterministic (E-Type: $\mathrm{Cu}-\mathrm{Mo}$ grades, $\mathrm{Cu}$ recovery) block models are used as inputs to mine planning process, in addition to a set of economic (such as prices and costs) and technical (as slope angles on pit walls, and bounds on resource consumption) parameters. By following the schemes given by Equations (1)-(4), a set of optimal pits are computed (one per scenario) by using a customized version of the Pseudoflow algorithm developed by [46] and from them a probabilistic final pit is chosen. Then, by using the pit limit obtained and applying the four scheduling schemes given by Equations (14), (23) and (24), a direct block scheduling approach is developed: (i) one as base case by using a (SCHED) model and ETInc heuristic algorithm, and (ii) a stochastic direct block scheduling, by solving (STO) model with an ETInc heuristic algorithm as well. Finally, a risk analysis is performed on the obtained results to test the designs sensitivity to uncertainty on a set of key performance indicators, such as ore tons, net present value, etc. In order to compare the results, the deterministic solution obtained from (SCHED) is assessed into (STO) fixing the values of extraction variables and solving for deviation variables.

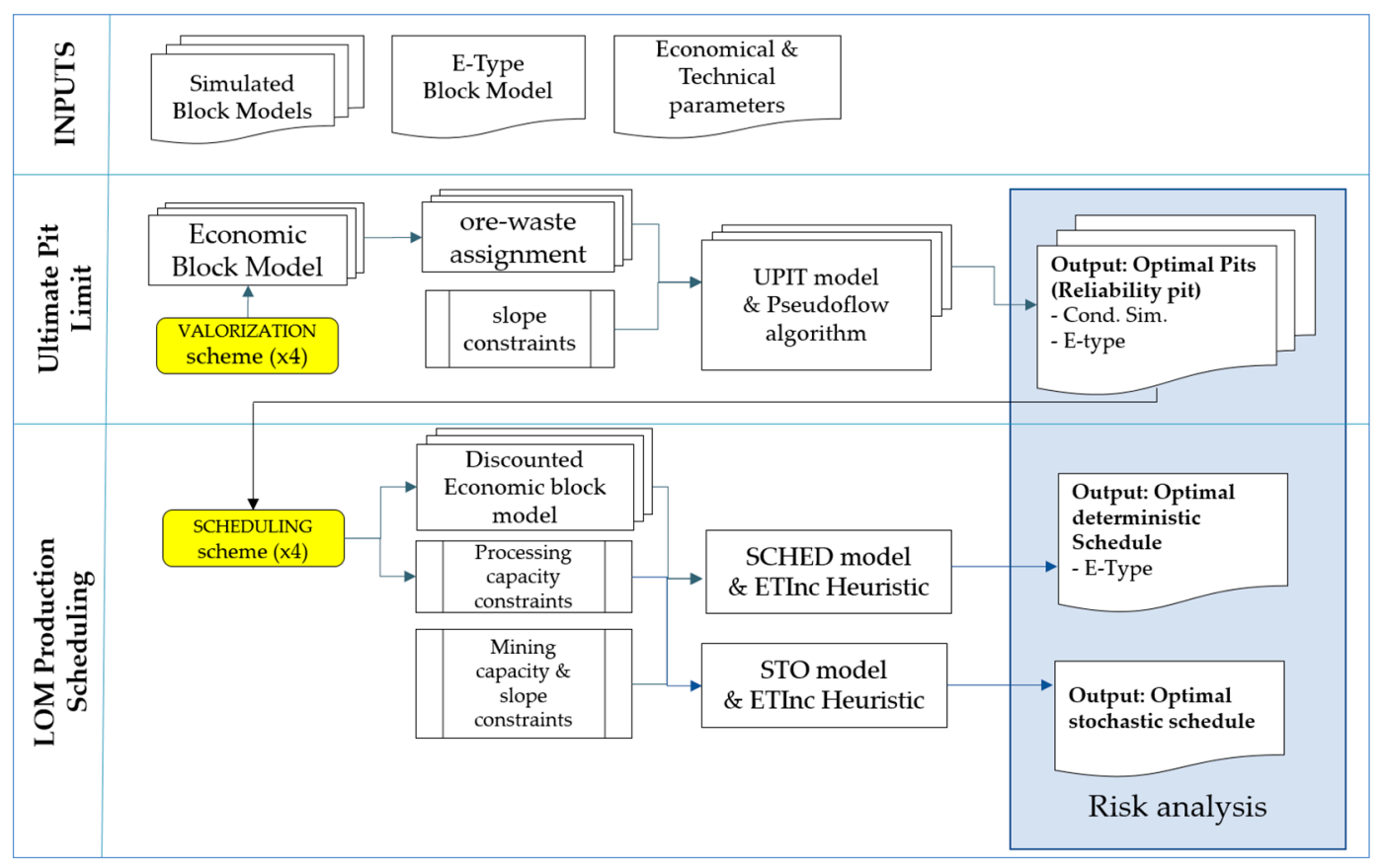

Figure 5. Flow chart representing the proposed methodology. 


\section{Case Study and Results}

\subsection{Case Study}

In this section the details about the case study are given, such as block model, geometallurgical variables that are simulated, parameters used for economic evaluation and technical constraints.

\subsubsection{Block Model}

The block model has 2,313,676 blocks of dimensions $20 \mathrm{~m} \mathrm{E,} 10 \mathrm{~m} \mathrm{~N}$ and $15 \mathrm{~m} \mathrm{Z}$. The original block model of the mining company was generated using an estimation by kriging, but for confidentiality reasons, the real data (kriging estimation) cannot be shown. Figure 6 shows the initial topography of the deposit, with a greater depth in the southern sector. This block model comes from a porphyry deposit, which produces copper and molybdenum concentrates from sulfide ores. The sulfide ore is sent to the processing plant which comprises a primary crusher, a grinding plant (Semi-Autogenous Grinding mill- or SAG mill, balls mills and pebble crusher) and a concentration plant with collective and selective flotation for separating copper and molybdenum concentrates as final products.

\subsubsection{Simulated Geometallurgical Variables}

The simulated variables are classified in two groups: the ore grades of the elements of economic interest and geometallurgical parameters that predict the metallurgical performance of the ore according to its geological properties. The following variables have been characterized and regionalized:

- Grades: $\mathrm{Cu}(\%)$ and $\mathrm{Mo}$ (gr/ton or ppm),

- Cu metallurgical recovery,

- Throughput rate (TPH): this variable predicts the tons per hour that can be processed in the milling circuit and it based on grindability test data (see Section 1.2.3) and the current operational configuration.

These variables have been simulated independently, using geostatistical techniques, because we did not find clear correlations among them. In detail, they were performed to assess the uncertainty of each grade and geometallurgical variables, and were built on a fine grid using a total of 24 nodes. Gaussians variables were obtained by applying normal scores transformation to the original data, and these transformed variables were independently simulated using sequential Gaussian simulation to generate $|R|=50$ realizations. Subsequently, the simulated values were back transformed to the original units of the data and regularized to block support. For the geometallurgical variables, no considerations were made about non-linear upscaling from point-to-block support. Nevertheless, all the simulated models were validated using the original data in the samples, showing consistent results. Within the validations performed, the statistics and variograms per estimation domains were reviewed with respect to the sample data, where it was verified that the actual spatial distribution is captured in the simulation models. Figures 7 and 8 show a plan view of the realization 1 of the deposit with the associated histogram and some statistics. As can be seen in Figure 7, $\mathrm{Cu}$ and Mo grade variables present an asymmetric distribution with a large number of low-grade blocks. On the other hand, according Figure 8, while metallurgical recovery values cover a wide range of values (between $25.7 \%$ and $94.8 \%$, with an interquartile range of $9.3 \%$ ), most data are concentrated to high values, with a median of $86 \%$. As for the values of TPH, these are widely distributed over the entire range of values from 2000 to 2979 tons $/ \mathrm{h}$.

The expected value model (E-Type), is calculated to be used in the mine planning process as base case. Note that there is one E-Type model per variable ( $\mathrm{Cu}$ grade, Mo grade and $\mathrm{Cu}$ metallurgical recovery), hence it must be clear what variable is being referred to when E-Type model is mentioned.

In terms of grade and ore tonnage uncertainty, Figure 9 shows the grade-tonnage curves, which detail the quantity and quality of the resources according to a copper cut-off grade. The curves are 
presented for (a) the average copper grade, and (b) average molybdenum grade. Also, the curves associated with the respective E-Type models are included, as well as the curves obtained from the set of realizations, including range between minimum and maximum. For example, it can be seen that the estimates of the E-Type models differ from the outputs. The tonnage of the E-Type model is overestimated for low cut-off grades and underestimated for high cut-off grades. On the one hand, the average copper grade is underestimated by E-Type model for the entire range of cutoff grades. On the other hand, the average molybdenum grade is overestimated by E-Type model for almost the entire range of cutoff grades, but for the minimum ones. In both cases, as the cutoff grade increases, so does the uncertainty in average grade.
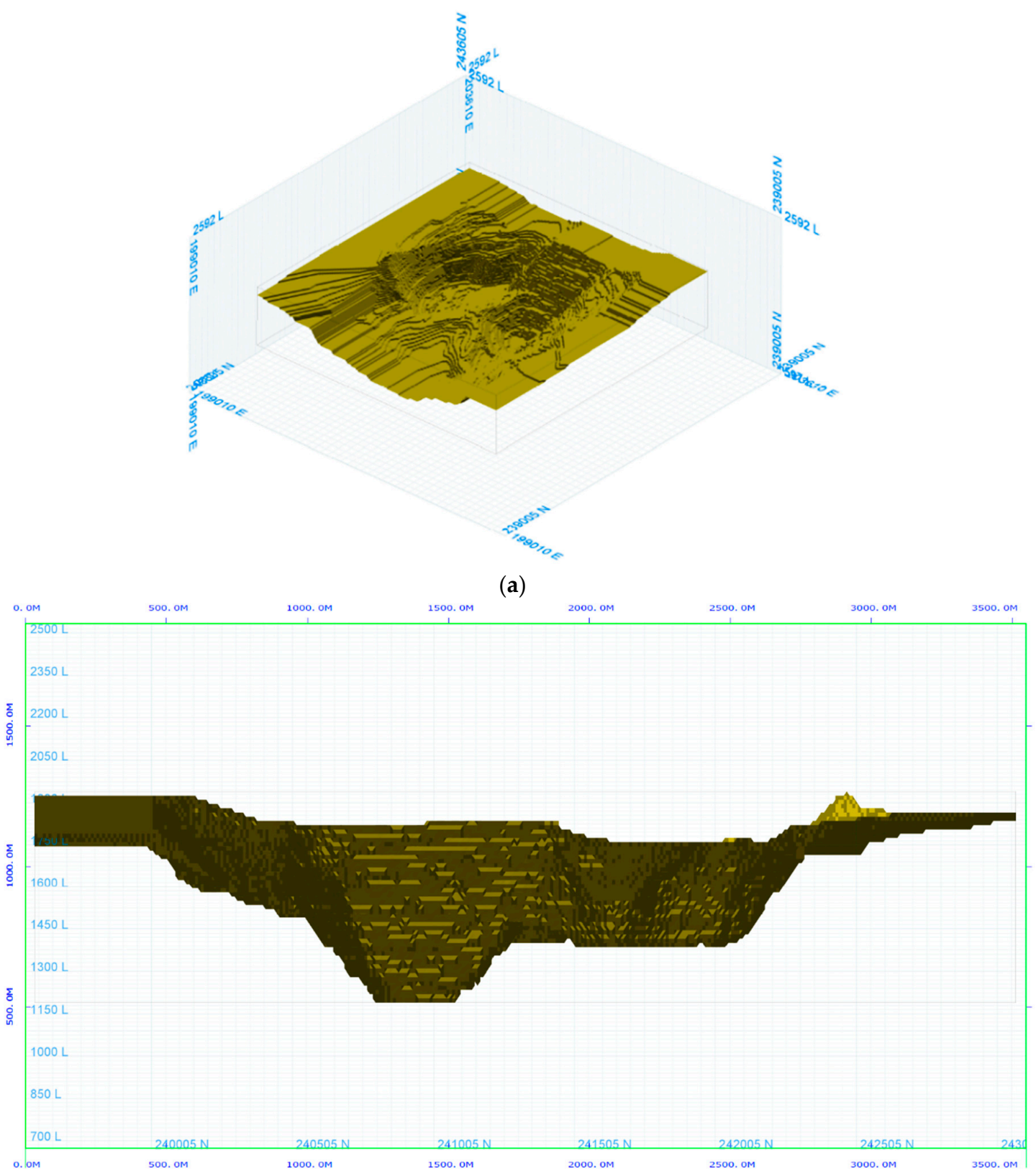

(b)

Figure 6. Topography's deposit. (a) Isometric view and (b) S-N section, E view. 

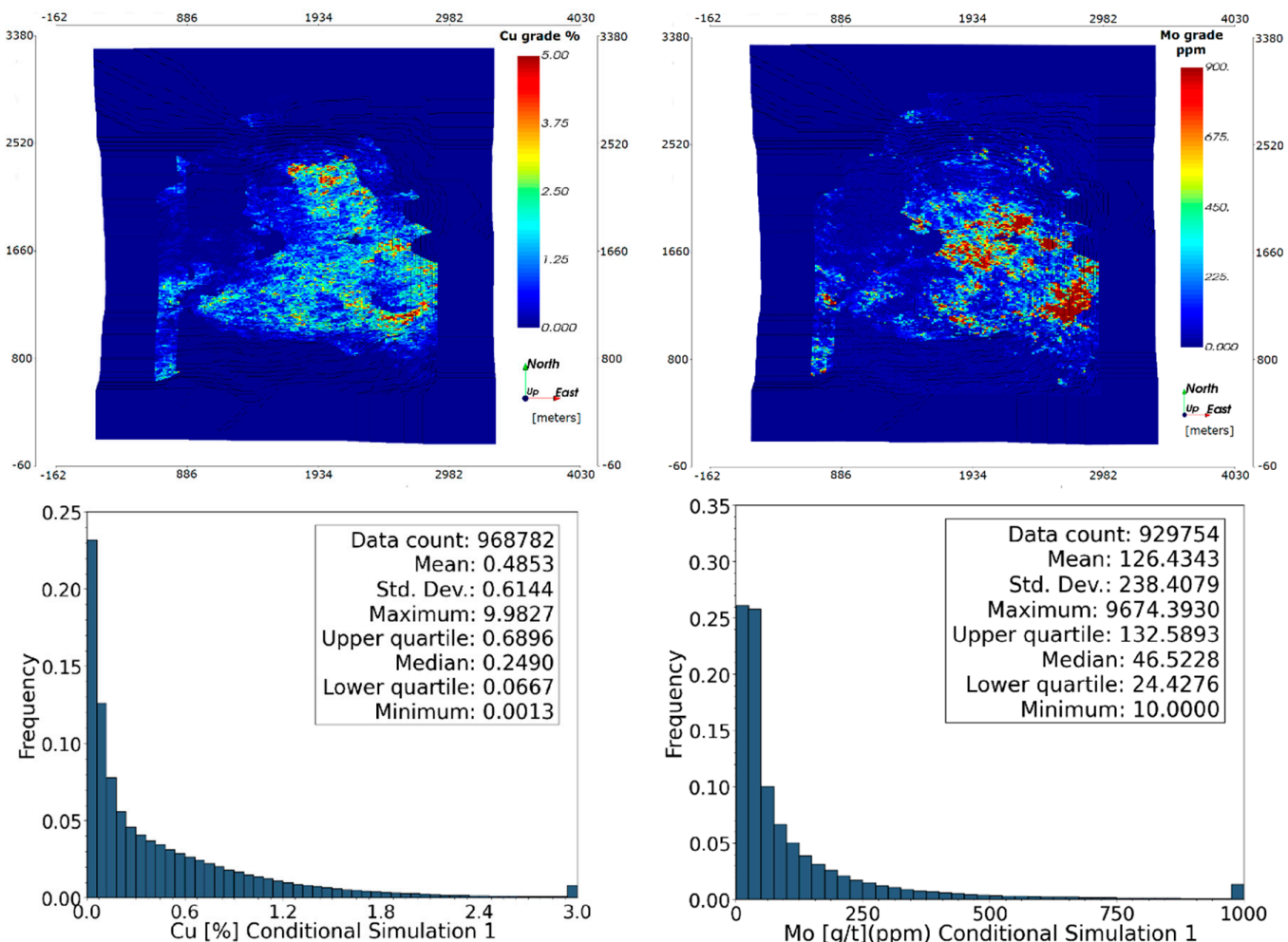

(a)

(b)

Figure 7. Plan view of geometallurgical models (top) with the associated histogram (bottom) for realization \#1. Variables: (a) Cu grade (\%) and (b) Mo grade (gr/ton).

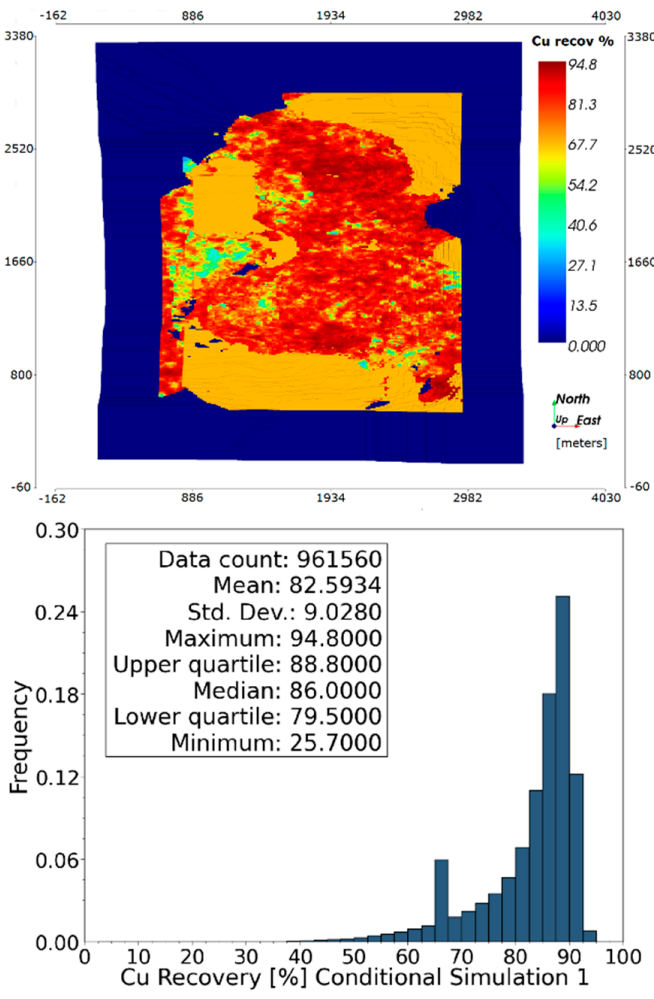

(a)

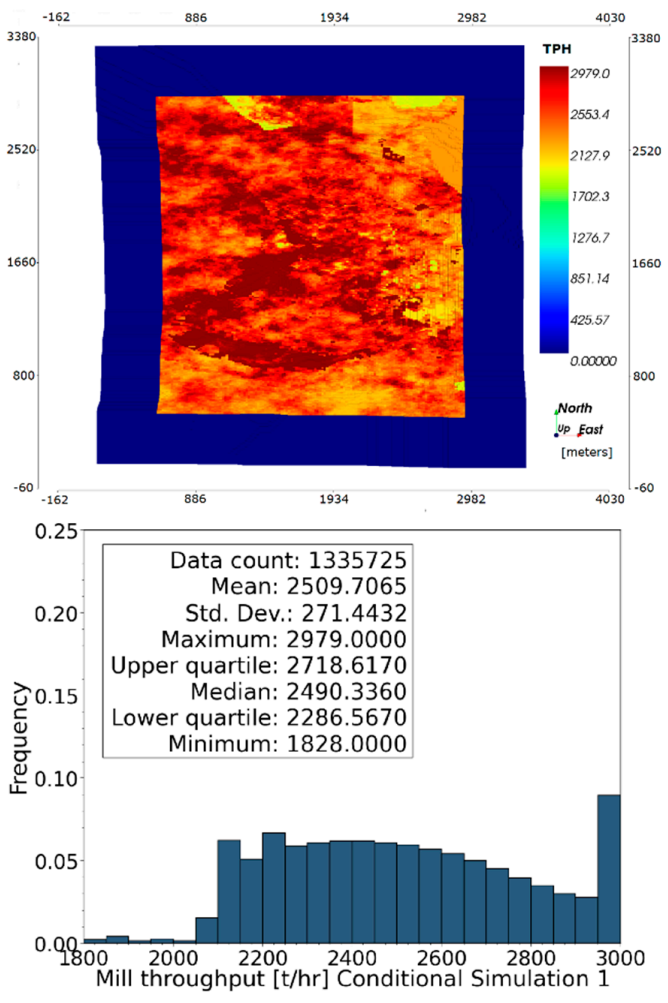

(b)

Figure 8. Plan view of geometallurgical models (top) with the associated histogram (bottom) for realization 1. Variables: (a) Cu metallurgical recovery (\%) and (b) throughput rate (ton/h). 


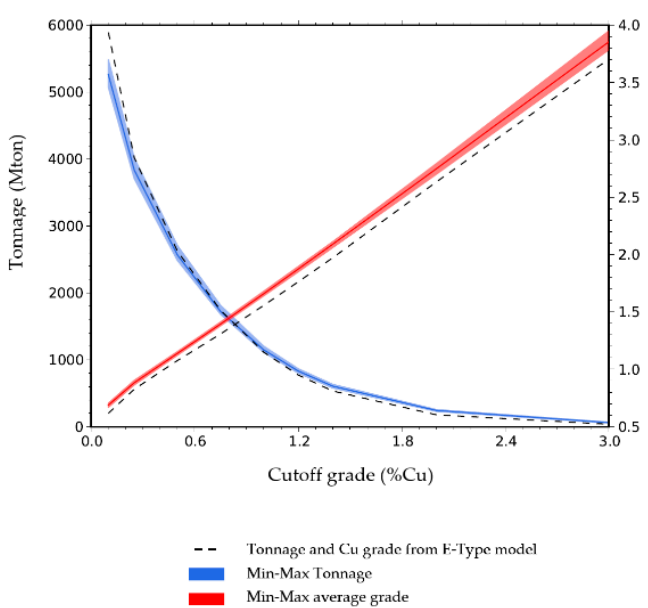

(a)

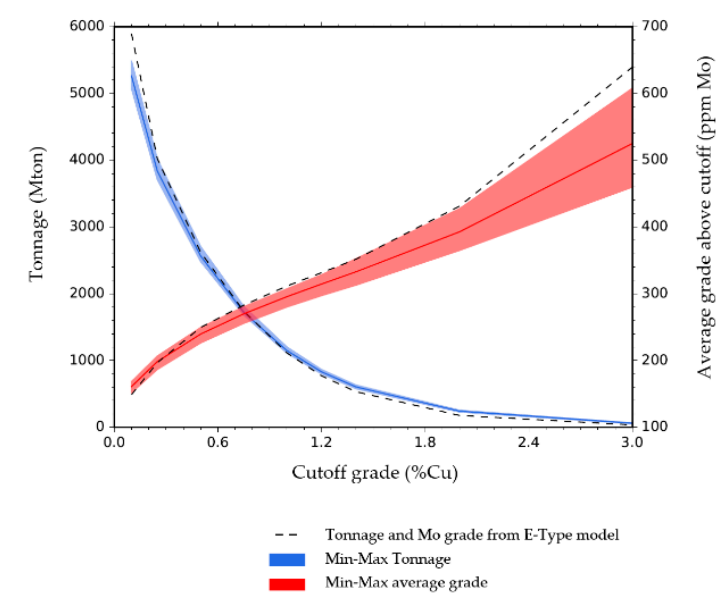

(b)

Figure 9. Grade-tonnage curves, with cutoff grade $(\% \mathrm{Cu})$. (a) Average grade above cutoff $(\% \mathrm{Cu})$, and (b) Average grade above cutoff (ppm Mo). Results from simulations and E-Type models.

\subsubsection{Economic Parameters}

The values of the parameters used for the generation of the economic block model are presented in Table 3. The metal prices correspond to long-term estimates, which remain constant for planning purposes. The costs come from the benchmark of Chilean mines with similar characteristics.

Table 3. Summary of economic parameters for block valuation applied in case study. Unitary costs to be considered: $\left({ }^{*}\right)$ scheduling Schemes 2 and 3 ; and $\left({ }^{* *}\right)$ scheduling Scheme 4 .

\begin{tabular}{cccc}
\hline Symbol & Unit & Parameter & Value \\
\hline$P^{c u}$ & USD $/ \mathrm{lb}$ & Cu price & 1.80 \\
$P^{m o}$ & $\mathrm{USD} / \mathrm{lb}$ & Mo price & 6.00 \\
$S C^{c u}$ & $\mathrm{USD} / \mathrm{lb}$ & Cu selling cost & 0.40 \\
$S C^{m o}$ & $\mathrm{USD} / \mathrm{lb}$ & Mo selling cost & 1.72 \\
$M C$ & $\mathrm{USD} /$ ton & Mining cost & 3.79 \\
$P C$ & $\mathrm{USD} /$ ton & Processing cost (main) & 11.35 \\
$P C^{m o}$ & $\mathrm{USD} /$ ton & Mo processing cost & 15.58 \\
$c p^{-}\left(^{*}\right)$ & $\mathrm{USD} /$ ton & Unitary shortage cost & 30.00 \\
$c p^{+}\left(^{*}\right)$ & USD/ton & Unitary surplus cost & 30.00 \\
$c p^{-(* *)}$ & $\mathrm{USD} / \mathrm{h}$ & Unitary shortage cost & $70,000.00$ \\
$c p^{+}\left(^{* *}\right)$ & $\mathrm{USD} / \mathrm{h}$ & Unitary surplus cost & $70,000.00$ \\
\hline
\end{tabular}

\subsubsection{Technical Parameters}

The values of the operational technical parameters used for the generation of the economic block model are presented in Table 4 . In this case, the average values for the processing time $H$ was calculated from the simulated models considering only the material that was classified as mineral. In order to generate the cone of precedence for each block $b$, two parameters are necessary: (i) overall slope angle $\alpha$. and height $h$, measured as the number of benches above block $b$. The upper and lower bounds for operational resource constraints are also given. All other necessary information is provided as attributes of the block model. Note that some parameters are exclusive for production scheduling stage while others are for ultimate pit limit as well (see UPIT, SCHED and STO models). 
Table 4. Summary of technical parameters for case study. Bounds on processing capacity to be considered: $\left({ }^{*}\right)$ scheduling Schemes 2 and 3 ; and $\left({ }^{* *}\right)$ scheduling Scheme 4.

\begin{tabular}{cccc}
\hline Symbol & Unit & Parameter & Value \\
\hline$R^{m o}$ & - & Mo metallurgical recovery & 0.55 \\
$H$ & hr/block & Average processing time & 3.18 \\
$\alpha$ & degree & Overall slope angle & 42.00 \\
$h$ & - & Height (number of upper benches) & 3.00 \\
$M_{t}^{-}$ & Mton & Lower bound mining cap. & 0.00 \\
$M_{t}^{+}$ & Mton & Upper bound mining cap. & 80.00 \\
$P_{t}^{-}\left(^{*}\right)$ & Mton & Lower bound process. cap. & 25.00 \\
$P_{t}^{+}\left(^{*}\right)$ & Mton & Upper bound process. cap. & 40.00 \\
$P_{t}^{-}\left(^{* *}\right)$ & hour & Lower bound process. cap. & $10,000.00$ \\
$P_{t}^{+}\left(^{* *}\right)$ & hour & Upper bound process. cap. & $15,710.00$ \\
$|\mathrm{~T}|$ & year & Planning horizon & 30.00 \\
$d$ & - & Discount rate & 0.10 \\
\hline
\end{tabular}

\subsection{Results}

\subsubsection{Ultimate Pit Limit: Key Indicators Results and Risk Analysis}

For each scheme (see Table 2) a risk analysis in terms of total economic value, tonnages and copper and molybdenum metal contents is carried out using each optimal pit obtained from 50 simulated and E-Type models. Table 5 shows key indicators such as economic value, rock and ore tonnages, and copper and molybdenum metal contents. For each scheme, the respective indicator was averaged and coefficient of variation (CV) along the set of realizations are showed. All schemes were re-evaluated by using the economic model of Scheme 3 for comparison.

Table 5. Key indicators such as value, tonnages of rock, ore, $\mathrm{Cu}$ and Mo metal contents (average and coefficient of variation) from ultimate pit limits obtained by different schemes. The economic values for Schemes 1,2 and 4 were re-evaluated by using the economic model of Scheme 3 for comparison.

\begin{tabular}{ccccccccccc}
\hline \multirow{2}{*}{ Scheme } & \multicolumn{2}{c}{$\begin{array}{c}\text { Undiscounted } \\
\text { Value (MUSD) }\end{array}$} & \multicolumn{2}{c}{ Rock (Mton) } & Ore (Mton) & Cu Metal (Mton) & \multirow{2}{*}{ Mo Metal (Kton) } \\
\cline { 2 - 12 } & Avg & CV\% & Avg & CV\% & Avg & CV\% & Avg & CV\% & Avg & CV\% \\
\hline 1 & 9453 & - & 3071 & - & 1433 & - & 17.5 & - & 388.1 & - \\
2 & 10,528 & 2.5 & 3372 & 4.1 & 1602 & 2.9 & 18.5 & 1.9 & 471.6 & 3.2 \\
3 & 10,725 & 3.1 & 3558 & 3.7 & 1682 & 2.4 & 18.9 & 2.5 & 467.2 & 3.8 \\
4 & 10,472 & 2.1 & 2972 & 3.2 & 1572 & 3.1 & 17.9 & 2.2 & 417.6 & 3.5 \\
\hline
\end{tabular}

It can be seen that the average total value among pits changes depending on the variables used in the block valuation process: the incorporation of uncertainty improves the economic value when compared to the deterministic E-Type variables. The biggest difference is between Schemes 1 and 3: when $\mathrm{Cu}$ and Mo grade uncertainty is added to the assessment, the expected value of the pits significantly increases $10.2 \%$. Additionally, considering the $\mathrm{Cu}$ metallurgical recovery model the expected value improves up to $12.3 \%$, which suggests that the use of a fixed or estimated recovery model may lead to biases in the metal production forecast and, therefore, in the estimation of economic benefit.

Larger (total tonnage) ultimate pits tend to be obtained when the uncertainty is incorporated in its definition. However, the sizes of pits obtained for Schemes 3 and 4 are also quite similar, with overlapping ranges of variability. The Scheme 4, on the other hand, generates smaller ultimate pits, which is mainly due to a reduction in waste tonnage for this case.

In most schemes and key indicator, E-Type model shows a poor performance regarding expected values obtained from simulations. 
Another important result is a consistent discrepancy between the predictions realized by simulated and E-Type models. The optimization of E-Type model leads to a pit with significantly lower both total values and tonnages, and the main cause of this is the smoothing of the copper grade distribution. As shown in Figure 10a, the average grade predicted by E-Type model is less than the expected for simulated models. In fact, for all cut-off grades the predicted values are lower and the predicted tonnages are similar between models, therefore, the predicted quantity of metal copper will be underestimated. Now if reserves defined by an optimal pit are considered, Figure 10b shows that E-Type model will overestimate the amount of ore tonnage for the cut-off into consideration.

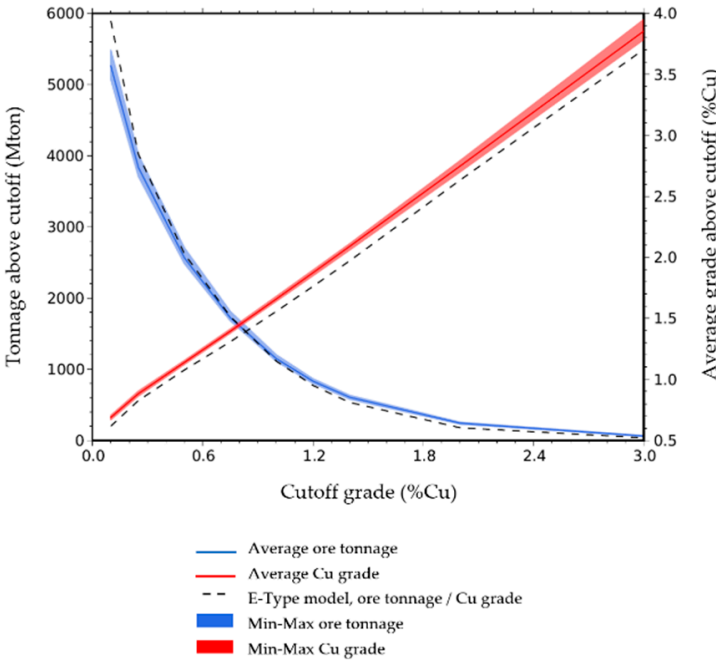

(a)

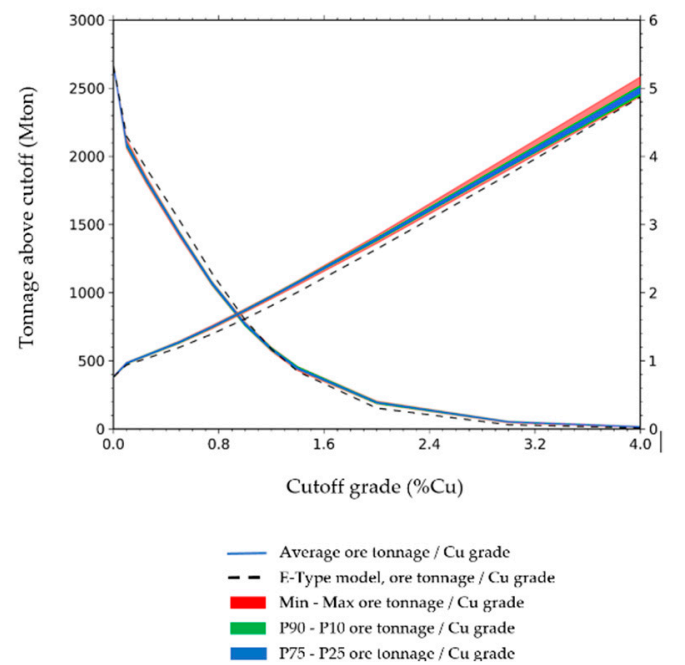

(b)

Figure 10. Grade-tonnage curve for estimated (E-Type) and simulated models, when considering (a) total resources, and (b) economic reserves within optimal ultimate pit limits defined for Scheme 2.

According Table 5, the use of the throughput rate model (TPH) in the economic block valuation for the ultimate pit limit does not seem to provide a relevant benefit in the results. In fact, the Scheme 4 leads to the poorest results when uncertainty is incorporated due to variability in processing times.

\section{Probability Model Results}

Once a set of final pits were obtained from realizations or simulated variables, a single final pit decision must be taken for later production scheduling. One approach for this is based on the probability of each block to belong to the ultimate pit limit. Probability models at $90 \%$, or reliability models as well for pit limits are presented in Figure 11 for comparison. Low uncertainty sectors in the pit (indicated in red color in the probability model) are located in the center of the deposit, which is precisely where the highest copper grades are located and which are associated with lower conditional coefficients of variation for these grades. The high uncertainty sectors are located in the contours of the pit. Finally, using a reliability model it is also possible to define alternatives of pit limits that satisfy the precedence requirements based on hybrid pits [50]: Table 6 shows the tonnages of potential pit limits, including blocks whose minimum threshold probability is reached. As expected, the tonnages increase as the minimum probability decrease. Note that the tonnages from most probable pit (probability 1) are less than those obtained with E-Type.

Then, the $90 \%$ reliability ultimate pit according Scheme 3 will be used as input for LOM production scheduling. 


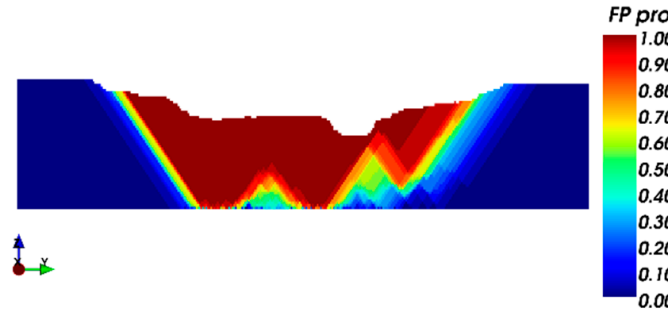

(a)

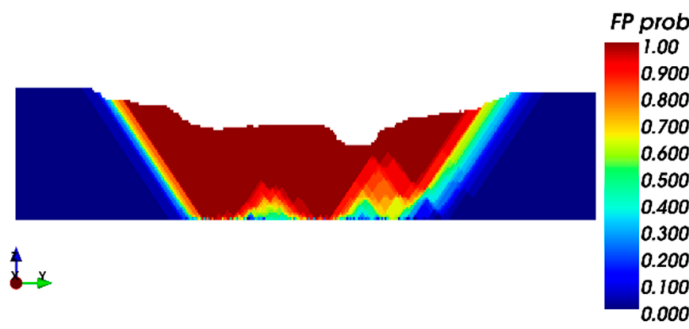

(c)

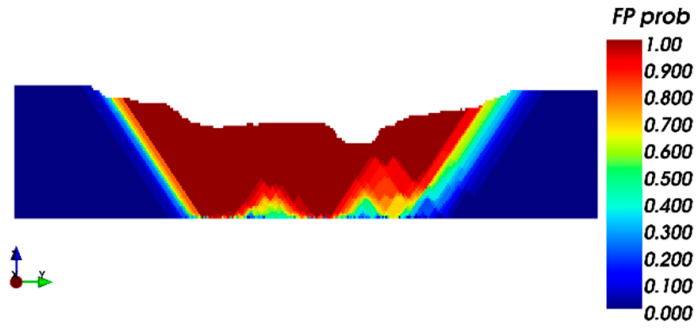

(e)

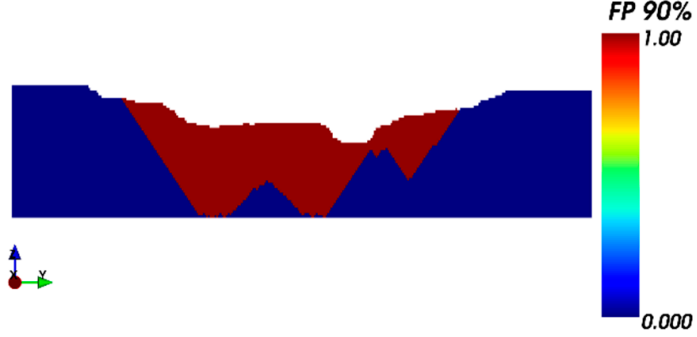

(b)

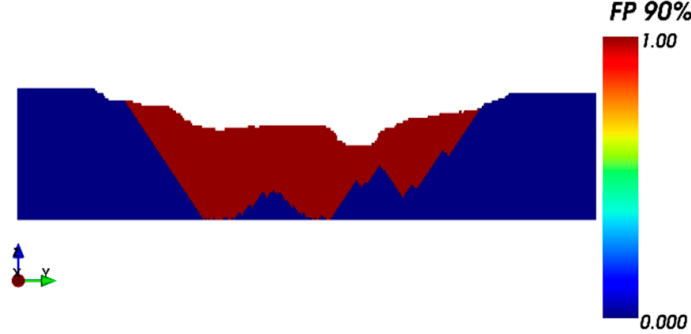

(d)

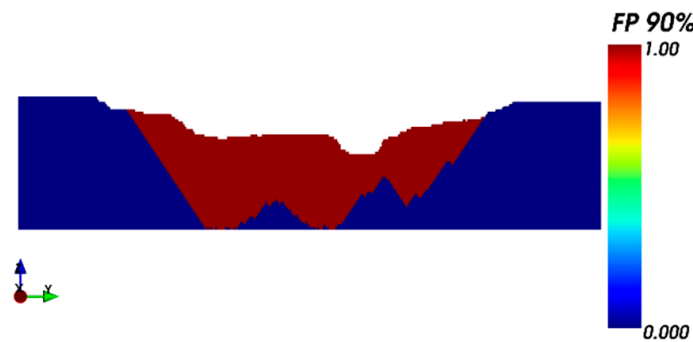

(f)

Figure 11. S-N sections, E views for probability models (FP prob) and a specific probabilistic ultimate pit limit for 90\% reliability (FP 90\%). (a) Scheme 2-probability final pit; (b) Scheme 2-90\% probability final pit; (c) Scheme 3-probability final pit; (d) Scheme 3-90\% probability final pit; (e) Scheme 4 - probability final pit; (f) Scheme 4-90\% probability final pit.

Table 6. Summary of ultimate pit limits by using hybrid pits methodology [50]. Values were re-evaluated by using the economic model of Scheme 3 for comparison.

\begin{tabular}{|c|c|c|c|c|c|c|c|c|c|}
\hline \multirow{2}{*}{$\begin{array}{l}\text { Minimum } \\
\text { Probability }\end{array}$} & \multicolumn{3}{|c|}{ Scheme 2} & \multicolumn{3}{|c|}{ Scheme 3} & \multicolumn{3}{|c|}{ Scheme 4} \\
\hline & $\begin{array}{l}\text { Value } \\
\text { (MUSD) }\end{array}$ & $\begin{array}{c}\text { Ore } \\
\text { (Mton) }\end{array}$ & $\begin{array}{l}\text { Rock } \\
\text { (Mton) }\end{array}$ & $\begin{array}{l}\text { Value } \\
\text { (MUSD) }\end{array}$ & $\begin{array}{c}\text { Ore } \\
\text { (Mton) }\end{array}$ & $\begin{array}{l}\text { Rock } \\
\text { (Mton) }\end{array}$ & $\begin{array}{l}\text { Value } \\
\text { (MUSD) }\end{array}$ & $\begin{array}{l}\text { Ore } \\
\text { (Mton) }\end{array}$ & $\begin{array}{l}\text { Rock } \\
\text { (Mton) }\end{array}$ \\
\hline 1.0 & 9062 & 1120 & 2320 & 9310 & 1184 & 2492 & 8633 & 988 & 2125 \\
\hline 0.9 & 9134 & 1199 & 2417 & 9422 & 1233 & 2509 & 8708 & 1005 & 2298 \\
\hline 0.8 & 9161 & 1274 & 2721 & 9501 & 1311 & 2718 & 8638 & 1072 & 2407 \\
\hline 0.7 & 9241 & 1295 & 2882 & 9638 & 1375 & 2925 & 8715 & 1163 & 2539 \\
\hline 0.6 & 9395 & 1342 & 2955 & 9793 & 1432 & 3046 & 8865 & 1203 & 2626 \\
\hline 0.5 & 9462 & 1473 & 3086 & 9941 & 1555 & 3173 & 8972 & 1298 & 2710 \\
\hline
\end{tabular}

\subsubsection{LOM Production Scheduling}

In this section the scheduling results are shown for each scheduling scheme. Results in terms of ore tonnage and economic value are obtained with each scheduling scheme, but they are assessed along all realizations into (STO) by using scheduling Scheme 3 for fair comparison.

Figure 12 shows ore and waste tonnages and NPV from production schedule obtained according (SCHED) by using scheduling Scheme 1. To avoid infeasibilities, no minimum processing capacities are imposed: the schedule that maximizes NPV will always try to saturate the maximum processing capacity, so implicitly the model should be adjusted well without this restriction, as long as there is sufficient material in each period. 


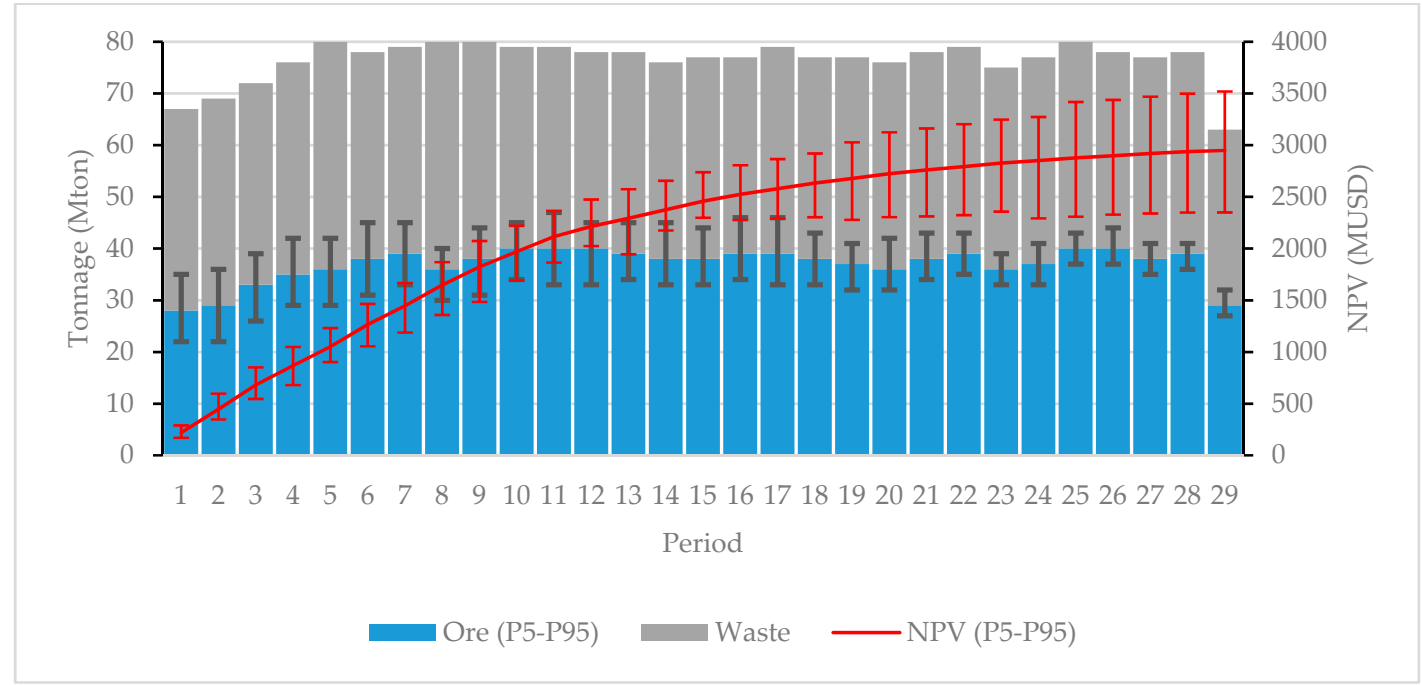

Figure 12. Ore and waste tonnages and net present value from production schedule obtained according (SCHED) by using scheduling Scheme 1. Results are assessed along all realizations into (STO) by using scheduling Scheme 3 for fair comparison.

Regarding the tonnages sent to the process, an expected feed of 36.9 (Mton/period) is observed, within the range imposed on average: there are large deviations in most of the periods, both underproduction in the first periods, but specially overproduction, which is presented with error bars (percentiles 5th and 95th, or P5 and P95 for simplicity hereafter). In this case, the cost associated to these deviations is 891.7 (MUSD). In terms of expected NPV, the scheduling Scheme 1 reaches 2949.3 (MUSD), with a 90\% central range (i.e., P95-P5) of 1170 (MUSD), that is, a 39.7\% of the expected return, therefore high variability and risk presents the schedule when the uncertainty in geology and metallurgy are not considered.

Now, Figure 13 shows ore and waste tonnages and NPV from production schedule obtained according (STO) by using scheduling Scheme 2, that is, when $\mathrm{Cu}$ and Mo grade uncertainty are incorporated: variability due to uncertainty is showed with error bars (percentiles, P5 and P95). In this case the model controls the deviations (shortage and surplus) minimizing their total cost. The average ore tonnage is 37.6 (Mton/period) and there are smaller deviations when compared with the scheduling Scheme 1, with a total discounted cost associated to these deviations of 396.5 (MUSD), a 55.5\% lower risk. In terms of expected NPV, the scheduling Scheme 2 reaches 3024.4 (MUSD), a 2.5\% greater than scheduling Scheme 1, with a $90 \%$ central range of 870 (MUSD), that is, a $28.7 \%$ of the expected return, therefore lower variability presents the schedule when grade uncertainty is considered.

As before, Figure 14 shows the obtained results but for scheduling Scheme 3, when $\mathrm{Cu}$ and Mo grade, and $\mathrm{Cu}$ metallurgical recovery uncertainties are incorporated in the economic block value and as input of (STO). Similar to scheduling Scheme 2, the model controls the ore tonnage deviations (shortage and surplus) minimizing their total cost. The average ore tonnage is 37.7 (Mton/period) and there are smaller deviations when compared with the scheduling Scheme 1, with a total discounted cost associated to these deviations of 389.8 (MUSD), a 1.7\% lower risk than scheduling Scheme 2. Since the model does not consider the deviation in metal recovered the potential improvements are due to consider the recovery uncertainty into the economic block valuation. Therefore, an extension of (STO) by considering simultaneously ore processing and recovered metal deviations would be more appropriated to assess the incorporation of recovery variable under uncertainty. However, the expected NPV of the scheduling Scheme 3 reaches 3162.2 (MUSD), a 4.6\% greater than scheduling Scheme 2, with a $90 \%$ central range of 890 (MUSD), that is, a $28.1 \%$ of the expected return, therefore similar variability in economic value presents the schedule when grade and recovery uncertainties are considered. 


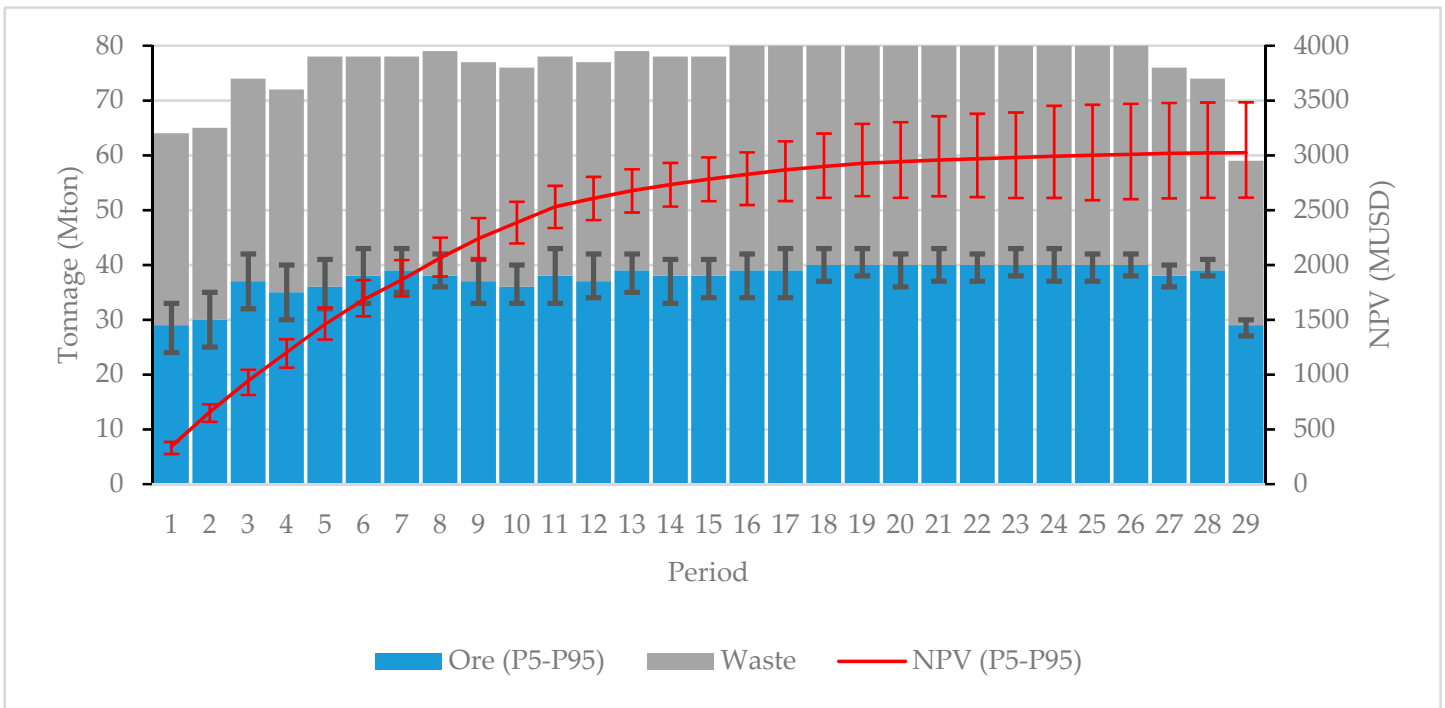

Figure 13. Ore and waste tonnages and net present value from production schedules obtained according (STO) by using scheduling Scheme 2. Results are re-evaluated by using scheduling Scheme 3 for fair comparison.

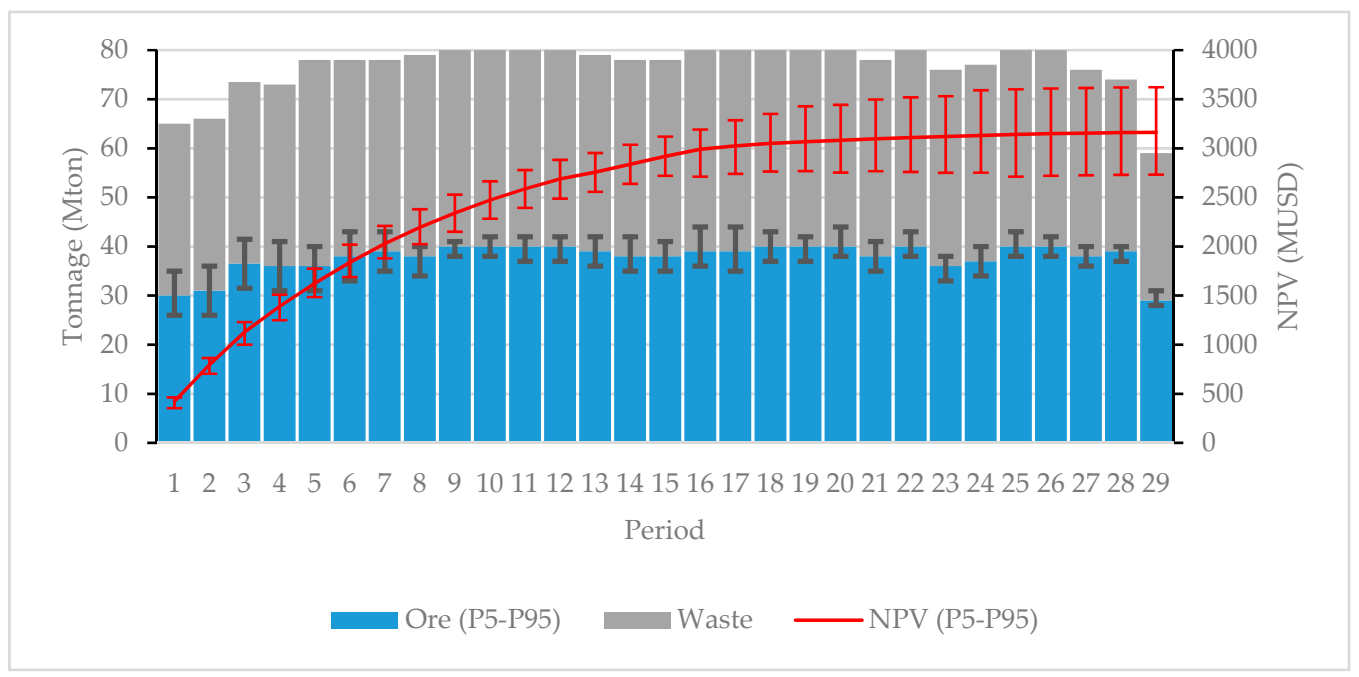

Figure 14. Ore and waste tonnages and net present value from production schedules obtained according (STO) by using scheduling Scheme 3.

Finally, Figure 15 presents the results when scheduling Scheme 4 is applied on (STO), that is, all variables ( $\mathrm{Cu}$ grade, Mo grade, $\mathrm{Cu}$ recovery and TPH) are simulated. Results are re-evaluated by considering in scheduling Scheme 3 the tonnage as TPH times average processing hours $(\mathrm{H})$ per block. In this case the resource consumption constraints are given in terms of processing hours per block instead of tons per block, and the model controls the deviations (in hours of shortage and surplus) minimizing their total cost. The corresponding average ore tonnage is 37.6 (Mton/period) and there are smaller deviations when compared with the scheduling Scheme 3, with a total discounted cost associated to these deviations of 280.4 (MUSD), a 68.5\% lower risk than scheduling Scheme 1 and 27.9\% lower risk than Scheme 3: larger ore tonnages appear in the early periods due to softer ore material, with shorter processing time, and harder ore material are processed at final of LOM with a longer processing time, therefore, to include TPH uncertainty helps to reduce the risk of non-compliance production objectives. In terms of expected NPV the scheduling Scheme 4 reaches 3227.3 (MUSD), a $2.1 \%$ greater than scheduling Scheme 3 by a better use of processing resources, with a $90 \%$ central range of 870 (MUSD). 


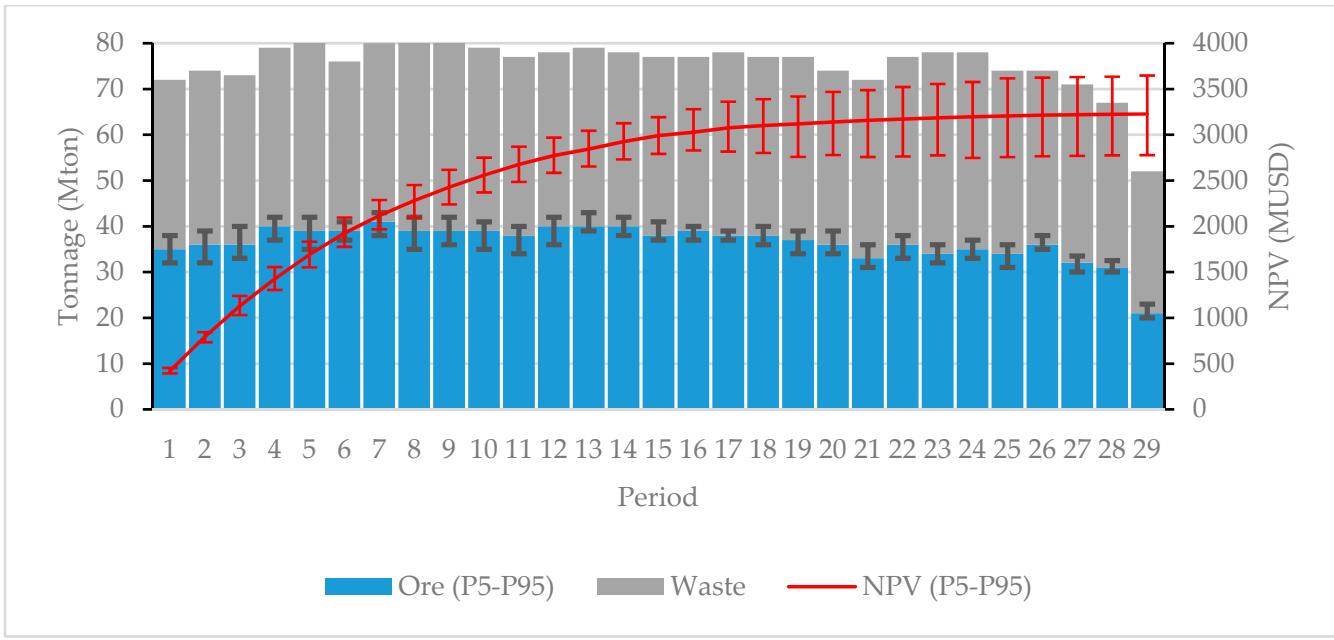

Figure 15. Ore and waste tonnages and net present value from production schedules obtained according (STO) by using scheduling Scheme 4. Results are re-evaluated by using Scheme 3 for fair comparison and a tonnage per block as TPH times $\mathrm{H}$.

In terms of the mining extraction sequence, Figure 16 shows section views of extraction sequences for each scheduling scheme: (a) 1 (deterministic), and (b), (c) and (d) stochastic 2, 3 and 4, with grades uncertainty, grades and recovery uncertainties, and grade, recovery and TPH uncertainties, respectively. In all cases the entire set of blocks inside ultimate pit had to be scheduled. It is interesting to note the differences in the extraction sequences, which shows that scheduling decisions do change as different degrees of information are incorporated. In all cases, the south-east sector is the most profitable because the sequences begin the extraction by that sector.

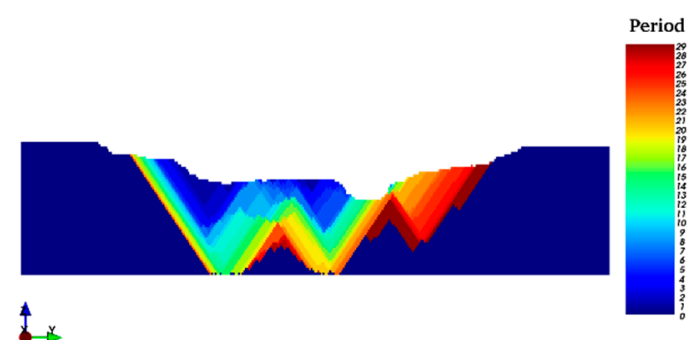

(a)

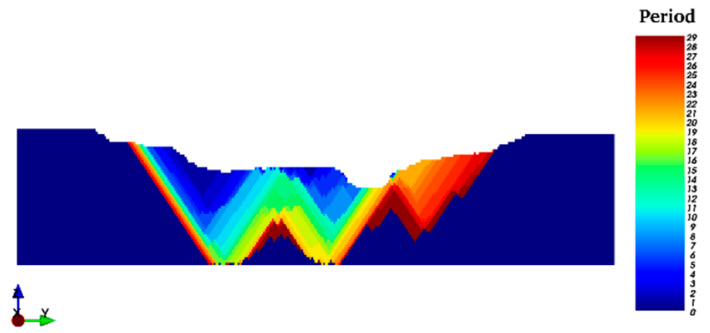

(c)

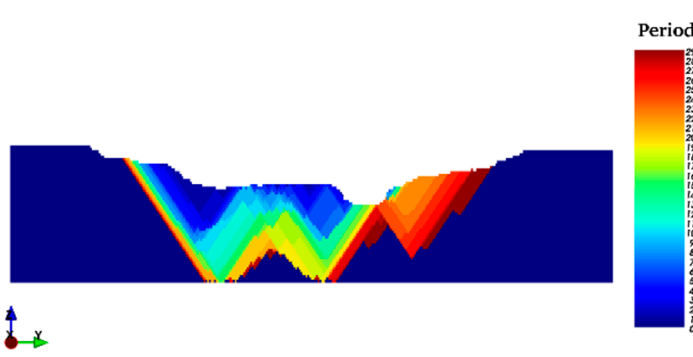

(b)

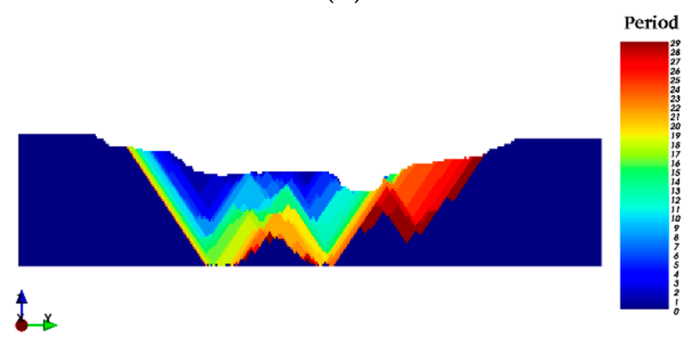

(d)

Figure 16. S-N sections, E views of the production schedules obtained by each scheduling scheme on $90 \%$ probability ultimate pit obtained by using Scheme 3. (a) Scheduling Scheme 1; (b) Scheduling Scheme 2; (c) Scheduling Scheme 3; (d) Scheduling Scheme 4.

\section{Discussion}

The discrepancies in value, tonnages, grades and stripping ratio observed in pit limits from E-Type models can be attributed to the smoothing effect of $\mathrm{Cu}$ grades. As observed in the grade-tonnage 
curves presented, for a given cut-off grade (approximately $0.5 \%$ for this case), the smoothing effect results in the E-Type model having a larger number of blocks classified as mineral and a smaller number of waste blocks. In addition, it was noted that the tonnage classified as ore contains a lower amount of copper metal and thus a lower average grade. As a result, the ore will be less profitable due to the higher processing costs that must be considered with respect to simulations to produce the same amount of metal copper. In this way, the ultimate pit that maximizes the benefit in the E-Type models will be smaller in size, with smaller metal content and therefore achieving a lower benefit. This justify the importance of considering uncertainty and geometallurgical variables in the early stages of the mining project. On the other hand, the outputs present a higher variability in the copper grades, which means that there are blocks of higher grades that allow the limits of the pits to be expanded and the extraction of a greater waste overload to be paid for.

In the case of LOM production stage, the scheduling Scheme 4 (considering four geometallurgical variables) presented the best results in terms of expected value. Table 7 shows a summary of expected net present value (Expected NPV, in MUSD), expected cumulative discounted deviation cost (Expected CDDC, in MUSD) and their respective relative variations (as a percentage) respect to result of scheduling Scheme 1: it shows how as more information of the simulated variables is included, the expected value increases and the risk of losses decreases. To include simulated geometallurgical variables can improve the expected return in this case study up to $9.4 \%$ and to reduce the risk associated to deviation of production objective in up to $68.6 \%$.

Table 7. Summary of main economic results of the case study.

\begin{tabular}{ccccc}
\hline \multirow{2}{*}{$\begin{array}{c}\text { Scheduling } \\
\text { Scheme }\end{array}$} & Expected NPV & Relative Variation & Expected CDDC & Relative Variation \\
\cline { 2 - 5 } & (MUSD) & CDDC \% & (MUSD) & CDDC \% \\
\hline 1 & 2949.3 & - & 891.7 & - \\
2 & 3024.4 & +2.5 & 396.5 & -55.5 \\
3 & 3162.2 & +7.2 & 389.8 & -56.3 \\
4 & 3227.3 & +9.4 & 280.4 & -68.6 \\
\hline
\end{tabular}

The schedules obtained from realizations, as opposed to the schedule from E-Type models, have processing times that tend to exceed the total hours available per period. This also shows a risk for production plans, since there are periods where there is no capacity to process all the available ore (surplus, or overproduction deviation), which puts the production forecasts at risk, affecting the economic value of the project. These increases in processing times may be due to hard rock conditions or ore increases due to the uncertainty of ore grades. One possible solution to this problem is the incorporation of stock-piles in the production planning process. However, the incorporation of stock-piles, would have a negative impact on the total value, as it would mean postponing the ore processing and incur extra re-handling costs. However, even so, a consideration of stocks would allow for effective control of ore variability, saturate processing times and maximize plant utilization. Other alternatives to this problem can be to reduce the staying times of the ore in the comminution circuits, but this would impact metallurgical recovery in the concentration stage, so it is a non-trivial decision that requires a further analysis.

\section{Conclusions}

The present study explores the practical uses of long-term geometallurgical models in the mine planning, incorporating simulated models that allow to consider the spatial variability and the uncertainty of the mineral deposit through a stochastic DBS approach, quantifying the risk and assessing the impact on mine planning decisions such as life-of-mine production scheduling along a number of simulated scenarios, serving as a guide for mining engineers to considers geometallurgical uncertainty in the mine planning decisions. This approach aims to generate a LOM production schedule with the following highlights: 
- Geological and geometallurgical scenarios are considered in one-run as input to the optimization process,

- the extraction period for each mining block is determined,

- the solution achieves the maximum discounted economic benefit of the mining business,

- the solution achieves the minimum risk of losses due to potential deviations from the production plan,

- the solution satisfies operational constraints, such as slope angles in pit walls and mining capacities.

The results show that the proposed methodology can improve the total value of the project and simultaneously to reduce the total cost associated to deviation of production objectives when compared with deterministic case. In the case study presented, a 9.4\% higher expected NPV is obtained when the grindability of the ore is considered through a throughput model, in addition to grade and recovery uncertainties, and the total cost of deviation of production objectives is reduced in $68.6 \%$. This improvement has been achieved incorporating a hourly processing constraint, which allows the saturation of throughput rate and scheduling giving priority to softer materials (lower processing times) with high recoverable metal. In this way, the most convenient blocks are first extracted in order to optimize the throughput over the life-of-mine.

The use of direct block scheduling models allows to generate production schedules to block support, thus it is usual that the obtained plans do not comply operational issues such as minimum spaces for equipment location or controlled stripping ratio per period, as can be seen in Figure 16. Therefore, a complete analysis should consider the operational design of the mine. A geometallurgical approach for key variables is fundamental to add value into the mine planning, hence future study should address the incorporation of these attributes into: new strategies for ore definition, mine design and an extended stochastic optimization approach, including metal content deviations for an explicit consideration of simulated $\mathrm{Cu}$ metallurgical recovery. The application of heuristic/metaheuristic/hyper-heuristic as presented by Lamghari and Dimitrakopoulos (see [51-53]) show a promising step forward to explore the application of this approach by using simulated geometallurgical variables.

Author Contributions: The authors contributions on this work are as follow: Conceptualization, N.M. and A.C.; Data curation, S.S. and A.C.; Investigation, N.M., S.S. and E.J.; Methodology, N.M., S.S., A.C. and E.J.; Project administration, N.M.; Resources, N.M. and A.C.; Software, N.M., A.C. and E.J.; Supervision, N.M. and A.C.; Validation, N.M., S.S., A.C. and M.A.; Visualization, S.S. and M.A.; Writing-original draft, N.M., S.S. and E.J.; Writing-review and editing, N.M. and E.J.

Funding: N.M., S.S., E.J. and M.A. were supported by CONICYT Basal Grant FB0809 (Advanced Mining Technology Center), Universidad de Chile. S.S. was also supported by GeoInnova.

Conflicts of Interest: The authors declare no conflict of interest.

\section{References}

1. Chilès, J.P.; Delfiner, P. Geostatistics: Modeling Spatial Uncertainty; John Wiley \& Sons: Hoboken, NJ, USA, 2009; ISBN 978-0-470-31783-9.

2. Lerchs, H.; Grossmann, I.F. Optimum Design of Open-Pit Mines. Tran. Can. Inst. Min. 1965, 58, 17-24.

3. Meagher, C.; Dimitrakopoulos, R.; Avis, D. Optimized open pit mine design, pushbacks and the gap problem-A review. J. Min. Sci. 2014, 50, 508-526. [CrossRef]

4. Jélvez, E.; Morales, N.; Askari-Nasab, H. A new model for automated pushback selection. Comput. Oper. Res. 2018. [CrossRef]

5. Heidari, S.M. Quantification of Geological Uncertainty and Mine Planning Risk Using Metric Spaces. Ph.D. Thesis, University of New South Wales Mining Engineering, Sydney, Australia, March 2015.

6. Walters, S.G. An overview of new integrated geometallurgical research. In Proceedings of the 9th International Congress for Applied Mineralogy, Brisbane, Australia, 8-10 September 2008; Australasian Institute of Mining and Metallurgy: Carlton, Australia, 2008; pp. 79-82. 
7. Deutsch, C.V. Geostatistical modelling of geometallurgical variables-Problems and solutions. In Proceedings of the 2nd AusIMM International Geometallurgy Conference, GeoMet, Brisbane, Australia, 30 September-2 October 2013; Dominy, S., Ed.; Australasian Institute of Mining and Metallurgy: Carlton, Australia, 2013; pp. 7-16.

8. Lund, C.; Lamberg, P. Geometallurgy-A tool for better resource efficiency. Eur. Geol. 2014, 37, 39-43.

9. Dominy, S.C.; O'Connor, L.; Parbhakar-Fox, A.; Glass, H.J.; Purevgerel, S. Geometallurgy-A Route to More Resilient Mine Operations. Minerals 2018, 8, 560. [CrossRef]

10. Cáceres, A.; Pelley, C.W.; Katsabanis, P.D.; Kelebek, S. Integrating Work Index to Mine Planning at Large Scale Mining Operations. In Proceedings of the 2nd International Conference on Mining Innovation-MININ 2006, Santiago, Chile, 23-26 May 2006; Ortíz, J., Ed.; DIMIN, UChile: Santiago, Chile, 2006; pp. 465-476.

11. Dunham, S.; Vann, J. Geometallurgy, geostatistics and project value-Does your block model tell you what you need to know? In Proceedings of the Project Evaluation Conference, Melbourne, Australia, 19-20 June 2007; Australasian Institute of Mining and Metallurgy: Carlton, Australia, 2007; pp. 189-196.

12. Coward, S.; Vann, J.; Dunham, S.; Stewart, M. The primary-response framework for geometallurgical variables. In Proceedings of the 7th International Mining Geology Conference, Perth, Australia, 17-19 August 2009; Dominy, S., Ed.; Australasian Institute of Mining and Metallurgy: Melbourne, Australia, 2009; pp. 109-113.

13. Contreras, R.E.; Ortíz, J.M.; Bisso, C. Mine planning considering uncertainty in grades and work index. In Proceedings of the 4th International Conference on Mining Innovation-MININ 2010, Santiago, Chile, 23-25 June 2010; Castro, R., Ed.; Gecamin: Santiago, Chile, 2010; pp. 129-136.

14. Coward, S.; Dowd, P.A.; Vann, J. Value chain modelling to evaluate geometallurgical recovery factors. In Proceedings of the 36th APCOM Conference, Porto Alegre, Brazil, 4-8 November 2013; Costa, J.F., Ed.; Fundação Luiz Englert: Porto Alegre, Brazil, 2013; pp. 288-298.

15. Coward, S.; Dowd, P.A. Geometallurgical models for the quantification of uncertainty in mining project value chains. In Proceedings of the 37th APCOM Conference, Fairbanks, AK, USA, 23-27 May 2015; Bandopadhyay, S., Ed.; SME: Englewood, CO, USA, 2015; pp. 360-369.

16. Dowd, P.A.; Xu, C.; Coward, S. Strategic mine planning and design: Some challenges and strategies for addressing them. Min. Technol. 2016, 125, 22-34. [CrossRef]

17. Kennedy, B.A. Surface Mining, 2nd ed.; SME: Littleton, CO, USA, 1990; ISBN 978-0-87335-102-7.

18. Sepulveda, E.; Dowd, P.A.; Xu, C.; Addo, E. Multivariate Modelling of Geometallurgical Variables by Projection Pursuit. Math Geosci. 2017, 49, 121-143. [CrossRef]

19. Monkhouse, P.H.L.; Yeates, G.A. Beyond Naïve Optimisation. In Advances in Applied Strategic Mine Planning; Springer: Cham, Switzerland, 2018; pp. 3-18. ISBN 978-3-319-69319-4.

20. Carrasco, P.; Chilès, J.-P.; Séguret, S.A. Additivity, metallurgical recovery, and grade. In Proceedings of the 8th International Geostatistics Congress, Santiago, Chile, 1-5 December 2008; Ortíz, J., Ed.; GECAMIN: Santiago, Chile, 2008.

21. Mwanga, A.; Rosenkranz, J.; Lamberg, P. Testing of Ore Comminution Behavior in the Geometallurgical Context-A Review. Minerals 2015, 5, 276-297. [CrossRef]

22. Yap, A.; Saconi, F.; Nehring, M.; Arteaga, F.; Pinto, P.; Asad, M.W.A.; Ozhigin, S.; Ozhigina, S.; Mozer, D.; Nagibin, A.; et al. Exploiting the metallurgical throughput-recovery relationship to optimise resource value as part of the production scheduling process. Miner. Eng. 2013, 53, 74-83. [CrossRef]

23. Dowd, P.A. Risk assessment in reserve estimation and open-pit planning. Trans. Inst. Min. Metall. Sect. A Min. Ind. 1994, 103, A148-A154.

24. Smith, M.; Dimitrakopoulos, R. The influence of deposit uncertainty on mine production scheduling. Inter. J. Surf. Min. Reclam. Environ. 1999, 13, 173-178. [CrossRef]

25. Journel, A.G.; Huijbregts, C. Mining Geostatistics; Academic Press: Cambridge, MA, USA, 1978; ISBN 978-0-12-391050-9.

26. Deutsch, J.L.; Palmer, K.; Deutsch, C.V.; Szymanski, J.; Etsell, T.H. Spatial Modeling of Geometallurgical Properties: Techniques and a Case Study. Nat. Resour. Res. 2016, 25, 161-181. [CrossRef]

27. Dimitrakopoulos, R. Advances in Applied Strategic Mine Planning; Springer: Cham, Switzerland, 2018; ISBN 978-3-319-69320-0.

28. Godoy, M. The Efficient Management of Geological Risk in Long-Term Production Scheduling of Open Pit Mines. Ph.D. Thesis, University of Queensland, Brisbane, Australia, December 2003. 
29. Leite, A.; Dimitrakopoulos, R. Stochastic optimisation model for open pit mine planning: Application and risk analysis at copper deposit. Min. Technol. 2007, 116, 109-118. [CrossRef]

30. Consuegra, F.R.A.; Dimitrakopoulos, R. Stochastic mine design optimisation based on simulated annealing: pit limits, production schedules, multiple orebody scenarios and sensitivity analysis. Min. Technol. 2009, 118, 79-90. [CrossRef]

31. Vielma, J.P.; Espinoza, D.; Moreno, E. Risk control in ultimate pits using conditional simulations. In Proceedings of the 34th APCOM Conference, Vancouver, BC, Canada, 6-9 October 2009; CIMM: Vancouver, BC, Canada, 2009; pp. 107-114.

32. Ramazan, S.; Dimitrakopoulos, R. Stochastic Optimisation of Long-Term Production Scheduling for Open Pit Mines with a New Integer Programming Formulation. In Advances in Applied Strategic Mine Planning; Springer: Cham, Switzerland, 2018; pp. 139-153, ISBN 978-3-319-69319-4.

33. Johnson, T.B. Optimum Open-Pit Mine Production Scheduling. Ph.D. Thesis, University of California, Berkeley, CA, USA, May 1968.

34. Morales, N.; Jélvez, E.; Nancel-Penard, P.; Marinho, A.; Guimaräes, O. A comparison of conventional and direct block scheduling methods for open pit mine production scheduling. In Proceedings of the 37th APCOM Conference, Fairbanks, AK, USA, 23-27 May 2015; Bandopadhyay, S., Ed.; SME: Englewood, CO, USA, 2015; pp. 1040-1051.

35. Caccetta, L.; Hill, S.P. An application of branch and cut to open pit mine scheduling. J. Glob. Optim. 2003, 27, 349-365. [CrossRef]

36. Chicoisne, R.; Espinoza, D.; Goycoolea, M.; Moreno, E.; Rubio, E. A New Algorithm for the Open-Pit Mine Production Scheduling Problem. Oper. Res. 2012, 60, 517-528. [CrossRef]

37. Jélvez, E.; Morales, N.; Nancel-Penard, P.; Peypouquet, J.; Reyes, P. Aggregation heuristic for the open-pit block scheduling problem. Eur. J. Oper. Res. 2016, 249, 1169-1177. [CrossRef]

38. Dimitrakopoulos, R. Stochastic optimization for strategic mine planning: A decade of developments. J. Min. Sci. 2011, 47, 138-150. [CrossRef]

39. Koushavand, B.; Askari-Nasab, H.; Deutsch, C.V. A linear programming model for long-term mine planning in the presence of grade uncertainty and a stockpile. Int. J. Min. Sci. Technol. 2014, 24, 451-459. [CrossRef]

40. Jélvez, E. Multistep Methodology for the Long-Term Open-Pit Mine Production Planning Problem under Geological Uncertainty. Ph.D. Thesis, Department of Mining Engineering, Universidad de Chile, Santiago, Chile, April 2017.

41. Dimitrakopoulos, R.; Farrelly, C.T.; Godoy, M. Moving forward from traditional optimization: Grade uncertainty and risk effects in open-pit design. Min. Technol. 2002, 111, 82-88. [CrossRef]

42. Godoy, M. A Risk Analysis Based Framework for Strategic Mine Planning and Design-Method and Application. In Advances in Applied Strategic Mine Planning; Springer: Cham, Switzerland, 2018; pp. 75-90. ISBN 978-3-319-69319-4.

43. Newman, A.M.; Rubio, E.; Caro, R.; Weintraub, A.; Eurek, K. A Review of Operations Research in Mine Planning. Interfaces 2010, 40, 222-245. [CrossRef]

44. Espinoza, D.; Goycoolea, M.; Moreno, E.; Newman, A. MineLib: A library of open pit mining problems. Ann. Oper. Res. 2013, 206, 93-114. [CrossRef]

45. Hochbaum, D.S.; Chen, A. Performance Analysis and Best Implementations of Old and New Algorithms for the Open-Pit Mining Problem. Oper. Res. 2000, 48, 894-914. [CrossRef]

46. Hochbaum, D.S. The Pseudoflow Algorithm: A New Algorithm for the Maximum-Flow Problem. Oper. Res. 2008, 56, 992-1009. [CrossRef]

47. Chandran, B.G.; Hochbaum, D.S. A Computational Study of the Pseudoflow and Push-Relabel Algorithms for the Maximum Flow Problem. Oper. Res. 2009, 57, 358-376. [CrossRef]

48. Hochbaum, D.S.; Orlin, J.B. Simplifications and speedups of the pseudoflow algorithm. Networks 2013, 61, 40-57. [CrossRef]

49. Jélvez, E.; Morales, N.; Nancel-Penard, P. Open-pit mine production scheduling: Improvements to MineLib library problems. In Proceedings of the 27th International Symposium on Mine Planning and Equipment Selection-MPES 2018, Santiago, Chile, 20-22 November 2018; Widzyk-Capehart, E., Hekmat, A., Singhal, R., Eds.; Springer: Cham, Switzerland, 2018; Chapter 18, pp. 223-232, ISBN 978-3-319-99220-4. [CrossRef] 
50. Whittle, D.; Bozorgebrahimi, A. Hybrid Pits-Linking Conditional Simulation and Lerchs-Grossmann Through Set Theory. In Proceedings of the Symposium on Orebody Modelling and Strategic Mine Planning, Perth, Australia, 22-24 November 2004; Dimitrakopoulos, R., Ed.; Australasian Institute of Mining and Metallurgy: Carlton, Australia, 2004; pp. 37-42.

51. Lamghari, A.; Dimitrakopoulos, R. Progressive hedging applied as a metaheuristic to schedule production in open-pit mines accounting for reserve uncertainty. Eur. J. Oper. Res. 2016, 253, 843-855. [CrossRef]

52. Lamghari, A.; Dimitrakopoulos, R. Network-flow based algorithms for scheduling production in multi-processor open-pit mines accounting for metal uncertainty. Eur. J. Oper. Res. 2016, 250, 273-290. [CrossRef]

53. Lamghari, A.; Dimitrakopoulos, R. Hyper-heuristic approaches for strategic mine planning under uncertainty. Comput. Oper. Res. 2018. [CrossRef]

(c) 2019 by the authors. Licensee MDPI, Basel, Switzerland. This article is an open access article distributed under the terms and conditions of the Creative Commons Attribution (CC BY) license (http://creativecommons.org/licenses/by/4.0/). 